\title{
The evolution of species concentrations in turbulent premixed flames crossing the soot inception limit
}

\author{
H. Shariatmadar ${ }^{\mathrm{a}}$, F. Hampp ${ }^{\mathrm{a}, \mathrm{b}}$, R. P. Lindstedt ${ }^{\mathrm{a}, *}$ \\ ${ }^{a}$ Department of Mechanical Engineering, Imperial College, London, SW7 2AZ, UK \\ ${ }^{b}$ German Aerospace Center (DLR), Stuttgart 70569, Germany
}

\begin{abstract}
The current study quantifies the impact of equivalence ratio and rate of strain on the spatial distribution of major species and soot precursors in premixed turbulent ethylene flames crossing the soot inception limit. A back-to-burnt (BTB) opposed jet configuration is used to provide accurate control of the turbulent and chemical timescales. The upper nozzle features fractal grid generated turbulence and premixed ethylene/air mixtures with flames stabilised against well-defined hot combustion products emerging from the lower nozzle. The study combines simultaneous $\mathrm{PAH} / \mathrm{CH}_{2} \mathrm{O}-\mathrm{PLIF}$ and elastic light scattering (ELS) with probe sampling. Gas chromatography-mass spectrometry (GC-MS) and gas chromatography-thermal conductivity detection (GC-TCD) were used to quantify concentrations of major species and poly-aromatic hydrocarbons (PAHs). The laser based diagnostics show that the rate of strain exerts a dominant impact on the growth of soot particles with low turbulent Reynolds numbers $\left(50 \leq R e_{t} \leq 94\right)$ used to promote soot formation. The probe measurements indicate that acetylene, $1-$ methylnaphthalene $(1-\mathrm{MN})$, $\mathrm{m} / \mathrm{z}=154, \mathrm{~m} / \mathrm{z}=276$ and benzo(a)pyrene correlate with soot formation and that the equivalence ratio is the controlling $\mathrm{PAH}$ growth parameter. It is further shown that the spatial extent of the PAH containing reaction zone exceeds three integral length scales.
\end{abstract}

Keywords: Soot formation, Turbulent flames, Laser diagnostics, Poly-aromatic hydrocarbons, Probe sampling

Supplemental material: (i) Uncertainty analyses (ii) Mass spectra (iii) Laminar flame data (iv) Tables with species concentrations

${ }^{*}$ Corresponding author. Tel: +442075947039

Preprint submitted to Combustion and Flame

October 5, 2021 


\section{Introduction}

2

Particulates generated from practical combustors feature complex chemical compositions that include polycyclic aromatic hydrocarbons (PAHs) [1-3]. Such emissions present health hazards $[4,5]$ and are subject to restrictions in aircraft and automotive industries [6-8]. For instance, particles from diesel exhaust include significant quantities of the Group 1 carcinogen benzo(a)pyrene (B(a)P) [9]. Such species are capable of efficiently bonding to, and be transported with, atmospheric particles [10]. The control of soot emissions from practical devices requires an understanding of the controlling parameters leading to their formation in turbulent flows [11].

Using laminar diffusion flames, Mercier et al. [12] concluded that soot nucleation coincided with the location of PAH dimers. However, the study [12] featured laser-induced incandescence (LII) at a wavelength of $1064 \mathrm{~nm}$, suitable for measuring mature rather than incipient soot particles, and, accordingly, the study does not provide clear evidence of a contribution of non-covalently bound PAH dimers to soot inception in flames. Johansson et al. $[13,14]$ showed that larger species can grow ahead of lighter ones and that PAH radical combination reactions provide fast routes for mass growth. Liu et al. [15] attribute the dominant reaction product to PAHs with 5-membered rings and such structures were directly observed by Schulz et al. [16] and Commodo et al. [17] using high-resolution atomic force microscopy (AFM) in a premixed $\mathrm{C}_{2} \mathrm{H}_{4}$-air flame. Liu et al. [18] showed the importance of coalescence of moderate-sized (planar) PAHs into cross-linked three-dimensional structures as a probable pathway to soot nucleation. The studies by Liu et al. [15, 18], Schulz et al. [16] and Commodo et al. [17] pro- 
vide results that are consistent with Johansson et al. [13, 14], supporting the role of resonance-stabilized radicals, predominantly formed from 5-membered ring structures, in the growth of covalently bound cross-linked adducts and soot inception. Tielens et al. [19] and Mao et al. [20] concluded that weak intermolecular interactions and van der Waals forces are responsible for bond formation arising from the majority of binary collisions between PAH radicals. However, experimental investigations can lead to a contrary conclusion for different flame conditions [21, 22]. Furthermore, numerous theoretical studies suggest that closed-shell PAH dimers have very short lifetimes under flame conditions except for species much larger than normally observed in flames [23-28]. Mass growth can result from direct PAH adsorption ${ }^{1}$ onto the soot surface [30-32]. In addition, Dworkin et al. [33] concluded that the predominant surface growth mechanism depends on combustion conditions. Lindstedt and Waldheim [34] used a sectional model to show that it is necessary to account for the collision efficiency change when moving from PAHs to the van der Waals enhanced limit associated with particulates.

The complex interactions of gas-phase and soot chemistry with turbulence is of particular concern given the comparatively long chemical timescales associated with soot formation and must be addressed using turbulent flame studies [35, 36]. Examples include the KAUST [36] and Adelaide [37, 38] jet diffusion flames. In the KAUST flames, soot particles size distributions were measured using a probe technique, while the Adelaide group applied laser diagnostics, including laser induced incandescence (LII), to measure soot vol-

\footnotetext{
${ }^{1}$ The term adsorption is preferred to condensation in light of the terminology review by Michelsen et al. [29]
} 
ume fractions. The latter study showed that the rate of strain and the flame volume exert a dominant influence. Extensive optical diagnostics have been used to study premixed turbulent sooting flames in the DLR swirl burner with flow velocities, soot volume fractions, PAH locations, temperatures and $\mathrm{OH}$ radical concentrations determined in a series of studies e.g. [39, 40]. The studies show that the spatial distributions of soot, $\mathrm{PAH}$ and $\mathrm{OH}$ are strongly dependent on the properties of the flow field.

Mueller and Pitsch [41] used large eddy simulation (LES) to study turbulence - chemistry interactions and found that small-scale interactions between turbulence, gas phase chemistry, and soot have a significant impact. Yoo and Im [42] performed a computational study of a non-premixed flame and showed that increased soot volume fractions in turbulent flames, as compared to steady laminar flames, may result from the rapid transport of soot particles out of high temperature regions rather than enhanced chemistry. Tian et al. [43] used a fully coupled transported PDF approach featuring a 78-dimensional joint-scalar space, including enthalpy, gas phase species and 62 soot sections to show that soot may be transported to fuel lean mixtures and highlighted a correlation with local extinction events.

The complexities of soot formation in turbulent flames suggests that the use of a flexible compact burner configuration with well-defined boundary conditions and precise control of flow characteristics is of significant advantage. Accordingly, a back-to-burnt opposed jet configuration $[44,45]$ is used to study the impact of changes in stoichiometry and rates of strain on the formation of soot in premixed turbulent ethylene-air flames crossing the soot inception limit [3]. Simultaneous elastic light scattering (ELS) and planar laser 
induced fluorescence $\left(\mathrm{CH}_{2} \mathrm{O} / \mathrm{PAH}-\mathrm{PLIF}\right)$ is used to complement probe measurements, featuring $\mathrm{GC}-\mathrm{MS}$ and $\mathrm{GC}-\mathrm{TCD}$, to provide quantitative data on the evolution of species concentrations in turbulent premixed flames crossing the soot inception limit. The parametric variations include, principally, (i) the stoichiometry of the upper nozzle reactant mixture $\left(1.8 \leq \phi_{U N} \leq 2.2\right)$ and (ii) the total rate of strain $\left(255 \leq a_{T}\left[\mathrm{~s}^{-1}\right] \leq 610\right)$. (iii) The impact of the temperature of the opposing hot combustion products $\left(1400 \leq T_{H C P}[\mathrm{~K}] \leq 1700\right)$ on the normalised PAH and ELS signals is also investigated.

\section{Experimental setup}

\subsection{Burner configuration and experimental conditions}

An opposed jet configuration is used to advance the fundamental understanding of particle inception, formation and oxidation in turbulent premixed ethylene/air flames. The burner configuration facilitates the precise adjustment of the chemical and turbulent timescales [44, 45]. Premixed ethylene/air mixtures emerging from the upper nozzle (UN) are stabilised against the lower nozzle (LN) hot combustion products [46] with the distance between the nozzles set to one diameter [47]. The UN is equipped with a cross fractal grid, located $50 \mathrm{~mm}$ upstream of the nozzle exit, that provides well developed multi-scale turbulence [48]. The LN provides hot combustion products $(\mathrm{HCP})$ originating from stoichiometric $\mathrm{H}_{2}$ flames diluted with $\mathrm{N}_{2}$ and stabilised on a perforated plate (PP) located $100 \mathrm{~mm}$ upstream of the LN exit [3]. The lower nozzle exit temperature $\left(T_{H C P}\right)$ is measured using a $50 \mu \mathrm{m}$ R-type thermocouple [49]. Nitrogen, emerging from the concentric shrouds of UN and LN nozzles, is used to shield the flames. The experimental 
conditions are summarised in Table 1 . The reference condition (REF) is defined as a $\mathrm{C}_{2} \mathrm{H}_{4}$ flame with equivalence ratio of $\phi_{U N}=2.0$ and a bulk rate of strain $\left(a_{b}=2 \mathrm{U} / \mathrm{H}\right)$ of $120 \mathrm{~s}^{-1}$ that is stabilised against a lower nozzle stream with a HCP temperature of $1500 \mathrm{~K}$. The total rate of strain $\left(a_{T}=a_{b}+a_{t}\right)$ was estimated using the approach of Kostiuk et al. [50] with $\mathrm{a}_{t}=\left(\varepsilon_{r} / \nu_{r}\right)^{1 / 2}$, where $\varepsilon_{r}$ is the rate of dissipation in the reactants, determined using the method of George and Hussein [51] as applied by Goh et al. [48], and $\nu_{r}$ the corresponding fluid viscosity.

Table 1: Experimental conditions used to study the impact of equivalence ratio, rate of strain and burnt gas temperature. The UN and LN fuels are $\mathrm{C}_{2} \mathrm{H}_{4}$ and $\mathrm{H}_{2}$, respectively, and $\phi_{L N}=1.0$ with $\alpha=\mathrm{X}_{H 2} / \mathrm{X}_{N 2}$, where $\mathrm{X}$ indicates a mole fraction, used to control $T_{H C P}, \mathrm{U}$ is the upper nozzle bulk velocity and $\mathrm{u}$ ' the velocity fluctuations. The reactant temperatures are $\mathrm{T}_{r}=320 \mathrm{~K}, \mathrm{~L}_{I}=3.9 \pm 0.2 \mathrm{~mm}$ is the integral length scale of turbulence, $\operatorname{Re}_{t}=u^{\prime} L_{I} / \nu$ the turbulent Reynolds number and $\mathrm{a}_{t}$ is the turbulent, $a_{b}=2 U / H$ the bulk and $\mathrm{a}_{T}=a_{t}+a_{b}$ the total rates of strain [50]. Values shown in brackets feature only $\mathrm{CH}_{2} \mathrm{O} / \mathrm{PAH}-\mathrm{PLIF}$ and ELS measurements.

\begin{tabular}{l|ccc}
\hline Variation & Reactants & HCP & Rate of Strain \\
\hline$\phi_{U N}[-]$ & $(1.7), 1.8,2.0,2.2$ & 2.0 & 2.0 \\
$a_{b}\left[\mathrm{~s}^{-1}\right]$ & 120 & 120 & $80,(105), 120,(135), 160$ \\
$\mathrm{a}_{t}\left[\mathrm{~s}^{-1}\right]$ & 300 & 300 & $175,(253), 300,(357), 450$ \\
$\mathrm{a}_{T}\left[\mathrm{~s}^{-1}\right]$ & 420 & 420 & $255,(358), 420,(492), 610$ \\
$\mathrm{Re}_{t}[-]$ & 72 & 72 & $50,(64), 72,(81), 94$ \\
$\mathrm{U}\left[\mathrm{m} \mathrm{s}^{-1}\right]$ & 1.8 & 1.8 & $1.2,(1.6), 1.8,(2.0), 2.4$ \\
$\mathrm{u}^{\prime}\left[\mathrm{m} \mathrm{s}^{-1}\right]$ & 0.30 & 0.30 & $0.21,(0.26), 0.30,(0.33), 0.39$ \\
$\mathrm{~T}_{H C P}[\mathrm{~K}]$ & 1500 & $1400,1500,1600,1700$ & 1500 \\
$\alpha[-]$ & 0.51 & $0.43,0.51,0.64,0.75$ & 0.51 \\
\hline
\end{tabular}

Figure 1 shows photographs illustrating the experimental conditions used to study the transition from lightly to heavily sooting flames at different rates of strain and equivalence ratios. The flame conditions, listed in Table 1, were selected to cover a range of scales affecting the formation of soot and soot precursors. The flame with a stoichiometry of $\phi_{U N}=1.7$ and $a_{T}=420 \mathrm{~s}^{-1}$ 


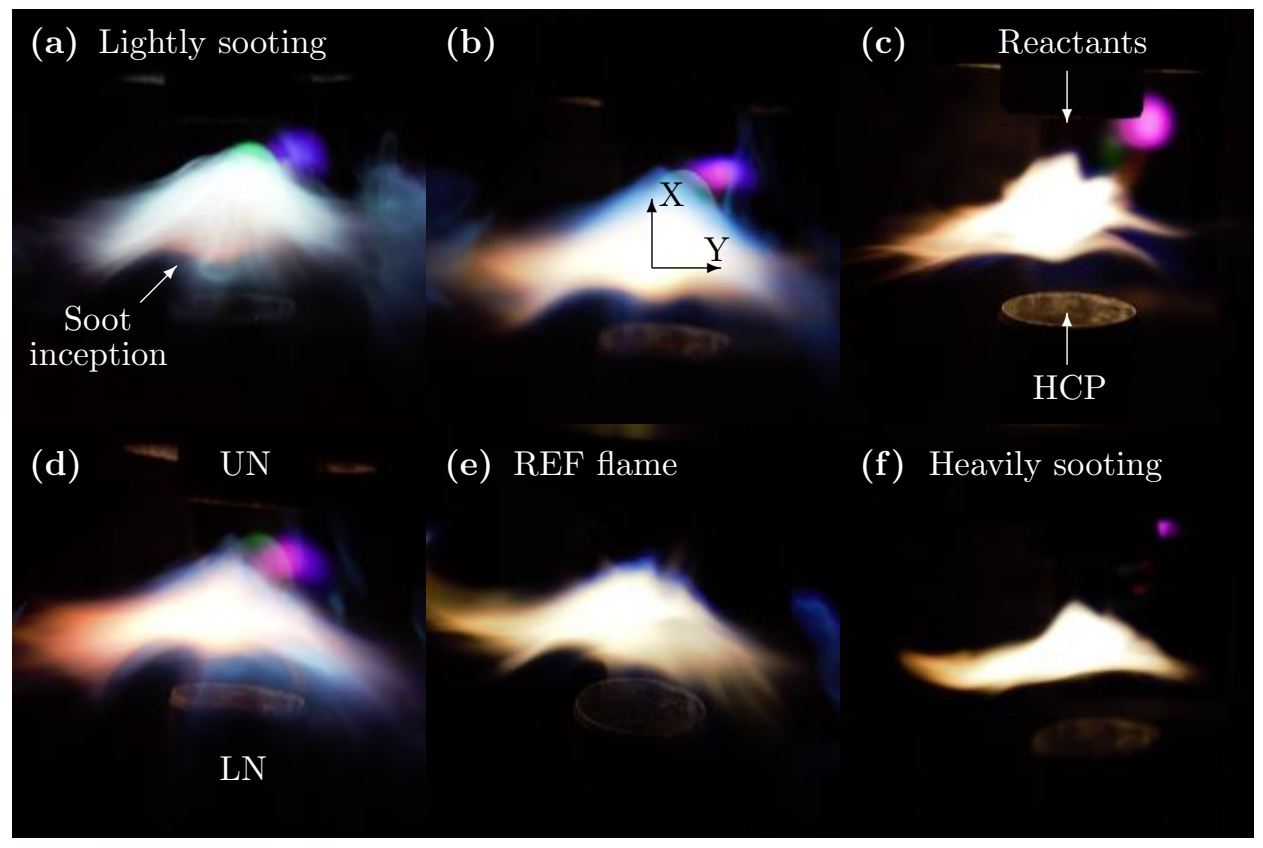

Figure 1: Sample photographs illustrating the experimental conditions used in the current study. Top row: $\phi_{U N}$ variation at a constant total rate of strain of $a_{T}=420 \mathrm{~s}^{-1}$ at (a) $\phi_{U N}=1.7$, (b) $\phi_{U N}=1.8$ and (c) $\phi_{U N}=2.2$; Bottom row: a variation of the rate of strain at a constant $\phi_{U N}=2.0$ at (d) $a_{T}=610 \mathrm{~s}^{-1}$, (e) $a_{T}=420 \mathrm{~s}^{-1}$ (Reference flame) and (f) $a_{T}=255 \mathrm{~s}^{-1}$.

is the lightest sooting condition shown and features strongly intermittent appearance of soot. The soot layer thickness increases significantly with a decreasing rate of strain and increasing equivalence ratio with the flames becoming bright yellow/orange at $\phi_{U N}=2.2$ and $a_{T}=255 \mathrm{~s}^{-1}$. Hampp and Lindstedt [52] have shown that the impact of the HCP temperature is comparatively modest for fuel-lean self-sustained flames that detach from the stagnation plane. The influence on soot formation is investigated below.

\subsection{Optical diagnostics setup}

The laser diagnostic setup has been presented in prior studies [3, 53] and is schematically depicted in Fig. 2. The measurements feature simul- 
taneous $\mathrm{CH}_{2} \mathrm{O} / \mathrm{PAH}-\mathrm{PLIF}$ and elastic light scattering (ELS). A frequency tripled (355 nm) Spectra-Physics Quanta-Ray Lab-150 Nd:YAG laser is used for $\mathrm{CH}_{2} \mathrm{O} / \mathrm{PAH}-\mathrm{PLIF}$ and a frequency doubled (532 nm) Litron Nano LG 175-10 Nd:YAG laser for the ELS measurements. The laser pulse energy is approximately $150 \mathrm{~mJ}$ at $355 \mathrm{~nm}$ and $30 \mathrm{~mJ}$ at $532 \mathrm{~nm}$. The two spatially overlapped light sheets, with a height of 18 and $27 \mathrm{~mm}$ and thickness of 100 $\mu \mathrm{m}$ (determined using burn marks), are located symmetrically around the theoretical stagnation plane. The top and bottom of the laser light sheets are clipped to minimise the spatial energy distribution across the sheet height. Excitation at $355 \mathrm{~nm}$ offers simultaneous detection of $\mathrm{CH}_{2} \mathrm{O}$ and $\mathrm{PAH}$ via LIF. The former can be used to identify the preheat zone and thus reaction onset. At the present turbulence conditions, the $\mathrm{CH}_{2} \mathrm{O}$ layer is continuous and upstream of any PAH appearance. Consequently, the $\mathrm{CH}_{2} \mathrm{O}$ layer can be spatially segregated from the PAH signal by means of a computer vision based image segregation technique $[46,53]$. It is worth pointing out that the segregated $\mathrm{CH}_{2} \mathrm{O}$ data is only used to indicate the flame front in the current study. On the other hand, excitation via the $3^{\text {rd }}$ harmonic (at $355 \mathrm{~nm}$ ) only facilitates probing of PAHs with three or more rings thus omitting prevalent smaller aromatics such as naphthalene. The latter can be included by using an excitation wavelength of $266 \mathrm{~nm}$ as shown by Geigle et al. [39, 40]. Bejaoui et al. [54] measured PAH concentrations in laminar flames using excitation at 266 and $355 \mathrm{~nm}$. A $50 \mathrm{~nm}$ shift towards $450 \mathrm{~nm}$, compared to $500 \mathrm{~nm}$, was noted with the latter excitation wavelength and attributed to different efficiencies. However, only modest differences in the resulting spatial distributions were shown, with both wavelengths indicating a rather homogeneous 
PAH pool under premixed conditions. The current probe measurements in Section 4.3 further supports this. Nonetheless, it is worth mentioning that the LIF measured PAH pool may be shifted towards the soot region $[55,56]$. However, excitation at $355 \mathrm{~nm}$ is adequate for the present purpose of delineating qualitative differences in the spatial PAH distribution. The relative high laser fluence at $355 \mathrm{~nm}$ suggests that incandescence is induced from the soot particles and superimposed onto the PAH - LIF signal [57]. For absolute soot volume fraction measurements it is preferable to use wavelengths $\geq 670 \mathrm{~nm}$ due to possible contamination by PAH signals [58]. However, in the present work only relative soot concentrations are measured and the data obtained by Simonsson et al. [58] at $532 \mathrm{~nm}$ showed the correct qualitative trend with comparatively modest absolute errors. In order to eliminate elastic scattering in the LIF detection systems, ELS is recorded 200 ns prior to LIF. Dichroic filters are used to spatially and spectrally segregate the signals. The ELS camera (LaVision LX 8M) is equipped with a $180 \mathrm{~mm} \mathrm{f/2.8} \mathrm{Sigma}$ lens and a narrow bandpass filter $(3 \mathrm{~nm})$ centred at $532 \mathrm{~nm}$. A LaVision intensifier relay optic unit and imager intense camera are used to record the PAH-PLIF. The latter is equipped with a $85 \mathrm{~mm}(\mathrm{f} / 1.2)$ lens and a $400 \mathrm{~nm}$ long-pass filter (Edmund Optics \#84-754). An intensifier gate time of $70 \mathrm{~ns}$ and a low gain level of $60 \%$ minimises flame luminescence and noise. The detection systems are calibrated and their coordinate systems superimposed using a multi-frequency target (Thorlabs \#R3L3S4P1). The spatial resolution of the detection system is determined to approximately $100 \mu \mathrm{m}$ using a NBS 1963A target. However, spatial filtering and superposition of the images degrade the effective spatial resolution to $250 \mu \mathrm{m}$ [53]. 


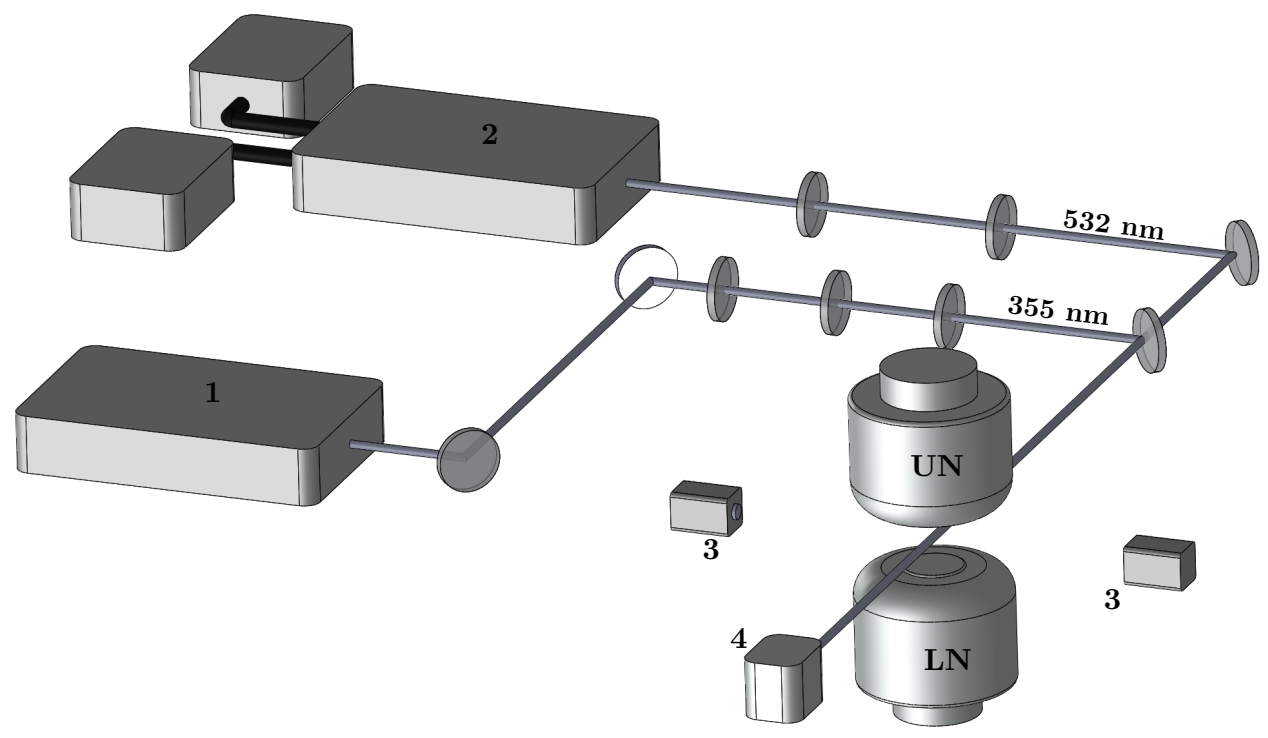

Figure 2: Laser diagnostics schematic: 1) Quanta-Ray laser; 2) Nano PIV; 3) Camera; 4) Beam dump; UN - Upper Nozzle; LN - Lower Nozzle.

\subsection{Sampling Probe}

The sampling system has been outlined by Shariatmadar et al. [3] and features a quartz probe (manufactured by Hilgenberg $\mathrm{GmbH}$ ) and dual nitrogen dilution ports. In order to minimise flame disturbances, a tip orifice diameter of $286 \mu \mathrm{m}$ and an opening angle of 20 degrees were used [59, 60]. Two large vacuum chambers with a combined volume of 36.8 litres are used to eliminate any pressure fluctuations or gradual shifts in the sampling pressure. A vacuum regulator is used to set a pressure differential of 20 mbar between the sampling line and the flame. This results in a constant sample flow rate of $3.125 \times 10^{-6} \mathrm{~kg} / \mathrm{s}$. The transfer line is equipped with a pressure transducer (UNIK 5000; GE Measurement and Control) and frequent leak tests were performed to preclude sample contamination. A sampling time of about 10,000 integral time-scales of turbulence is used (120 s) to ensure sta- 
tistical independence and collection is terminated by disconnecting the probe from the vacuum system. The sampling line assembly can be traversed in all directions using linear translation stages and the location is calibrated using the optical setup. The ELS camera determines the $\mathrm{X}$ and $\mathrm{Y}$ position (i.e. $\mathrm{X} / \mathrm{L}_{I}=0.5, \mathrm{Y} / \mathrm{L}_{I}=0$ ) and the laser light sheet determines the alignment of the probe tip with the theoretical stagnation point streamline $\left(\mathrm{Z} / \mathrm{L}_{I}=0\right)$. The origin $(0,0,0)$ is the theoretical stagnation point. The positioning of the sampling system (i.e. probe tip) on laboratory jacks and sliders enables a fine adjustment within an accuracy of $\sim 0.1 \mathrm{~mm}$. The sampling process is discussed further below.

\subsubsection{Probe effects}

To determine the quantitative impact of probe effects is challenging as the combined influence of the probe configuration and sampling conditions (i.e. the applied suction pressure $\Delta \mathrm{P}$ ) need to be taken into account in the evaluation of flame perturbations [61]. Shariatmadar et al. [3] performed an uncertainty analysis to quantify probe effects for the current sampling system with PAH-PLIF and ELS used to determine the flow perturbations at different suction pressures. The analysis shows that the mean PAH and ELS profile peak and location are not affected by the presence of the probe at suction pressures of 20 mbar as used here. At higher suction pressures, measurements progressively deviate from the undisturbed profiles.

\subsubsection{Probe clogging}

Clogging at the probe tip is a potential source of errors. The static pressure of the sampling line (pressure transducer) is recorded regularly for each 
data set. In a case of a pressure fluctuation or sudden pressure change in the sampling line, the experiment is stopped to check for any signs of probe clogging. Wang and co-workers [62], and Roberts and co-workers [36] used a fine needle/wire to resolve orifice clogging issues between experiments. Camacho et al. [62] reduced the sampling time $(50 \mathrm{~s})$ to avoid clogging at the probe tip. The sampling time was chosen to provide a compromise between size distribution smearing at short times and orifice clogging at long scan times. In the current study, a different approach was used to avoid experimental errors and potential probe cracking. The probe was disconnected from the vacuum suction and a reverse nitrogen flow used to direct soot particulates to the outside of the probe tip. The sampling line assembly was then traversed in the $\mathrm{X}$-direction towards the burnt gas state using the linear translation stage. This leads to the combustion of particles at the probe tip and any particles remaining in the sampling line were pushed out with the assistance of the nitrogen flow.

\section{Data analysis}

\subsection{Optical diagnostic}

Laser diagnostic images are shown in Fig. 3 for lightly and heavily sooting flames. The introduced image labelling is based on defined terminologies [3] with primary particles and aggregates referred to by the term "soot" as presented in the ELS and PAH-PLIF images. Due to the high laser fluence at $355 \mathrm{~nm}$, soot incandescence is likely to contribute to the LIF images [57]. A direct comparison of the PAH and ELS image pairs further supports this. The flame with an equivalence ratio of $\phi_{U N}=1.7$ corresponds to a lightly 


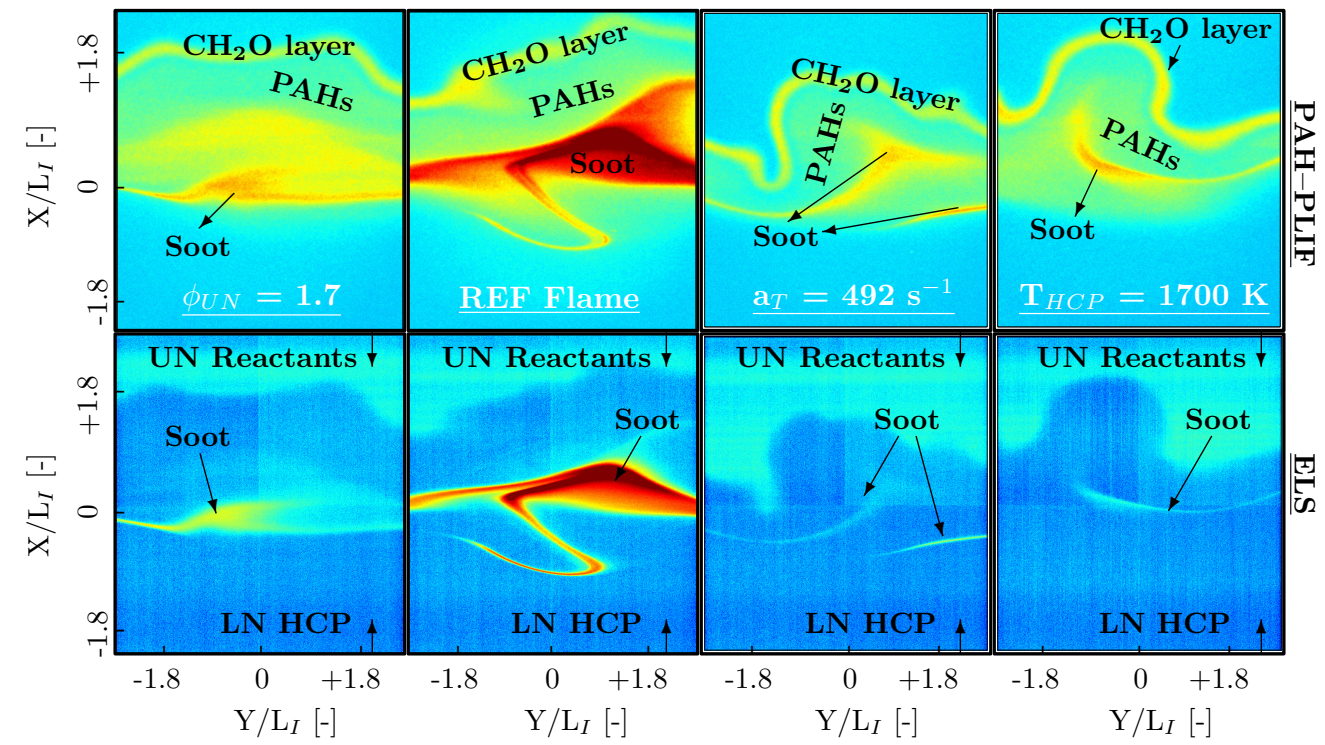

Figure 3: Laser diagnostic images obtained for $\mathrm{CH}_{2} \mathrm{O} / \mathrm{PAH}-\mathrm{PLIF}$ (top) and ELS (bottom). The relatively high laser fluence at $355 \mathrm{~nm}$ suggests that soot particle incandescence contributes to the PAH - LIF signal [57]. Thus, this data is likely to include contributions from PAHs infused on soot particles as well as gaseous species. $1^{\text {st }}$ column : $\phi_{U N}=1.7$, $\mathrm{a}_{T}=420 \mathrm{~s}^{-1}$ and $\mathrm{T}_{H C P}=1500 \mathrm{~K} ; 2^{\text {nd }}$ column $: \phi_{U N}=2.0, \mathrm{a}_{T}=420 \mathrm{~s}^{-1}$ and $\mathrm{T}_{H C P}=$ $1500 \mathrm{~K} ; 3^{\text {rd }}$ column : $\phi_{U N}=2.0, \mathrm{a}_{T}=492 \mathrm{~s}^{-1}$ and $\mathrm{T}_{H C P}=1500 \mathrm{~K} ; 4^{\text {th }}$ column $: \phi_{U N}$ $=2.0, \mathrm{a}_{T}=420 \mathrm{~s}^{-1}$ and $\mathrm{T}_{H C P}=1700 \mathrm{~K}$. Dark red indicates a high signal count and blue a low signal count in a.u.

sooting condition with a sporadic appearance of soot layers. By contrast, the REF flame $\left(\phi_{U N}=2.0\right)$ represents a flame with relatively thick soot layers. Soot nucleation, mass growth and PAH adsorption are enhanced considerably in the low-temperature region in the proximity of the stagnation plane $\left(\mathrm{X} / L_{I}\right.$ $=0.5)$ of the richer flame [63]. A comparatively higher intensity, shown in PAH-PLIF and ELS images, reinforces the evolution of the balance between formation and consumption over the reaction zone layer. 


\subsection{Sampling process}

\subsubsection{Major gaseous species}

The sampling process for gaseous species, schematically depicted in Fig. 4, is performed without using nitrogen dilution $[64,65]$. Tedlar bags are placed in the vacuum chamber to collect gaseous species [66] and a gas-tight syringe (purchased from ESSLAB) is used to inject the sample into the GC-TCD [67]. Measurements of gaseous species can be affected if the sample contains excess water vapour [68] and a filter unit consistent of quartz wool and sodium sulphate is used to remove water [69]. To avoid trapping of gas residues and eliminate cross-sample contamination, the sampling system is flushed at the end of each sampling process with nitrogen $(5 \mathrm{~L} / \mathrm{min})$ for $120 \mathrm{~s}$. The flushing gas is injected in a 1:1 split ratio into the sampling system using two dilution ports, i.e. at the probe tip and along the sampling line.

The chemical analysis is performed using a gas chromatograph (Agilent 7890A) equipped with a thermal conductivity detector (TCD). A HP-PLOT Q and a HP-Moleseieve column (helium carrier gas) are used to quantify the concentrations of selected $\mathrm{C}_{1}-\mathrm{C}_{4}$ hydrocarbons along with $\mathrm{CO}, \mathrm{CO}_{2}, \mathrm{~N}_{2}$ and $\mathrm{O}_{2}$. The GC-TCD was calibrated regularly with Scotty gas mixtures (purchased from Agilent Technologies LTD) containing these species [70]. The accuracy of the GC/TCD analysis and the reproducibility of the data was evaluated by repeating the sampling at constant flame and measurement positions. A standardised operational procedure was used to improve the reproducibility with each measurement point repeated at least five times. It was found that the repeatability was significantly enhanced by removing water vapour from gaseous sample and by repeating routine calibration steps 


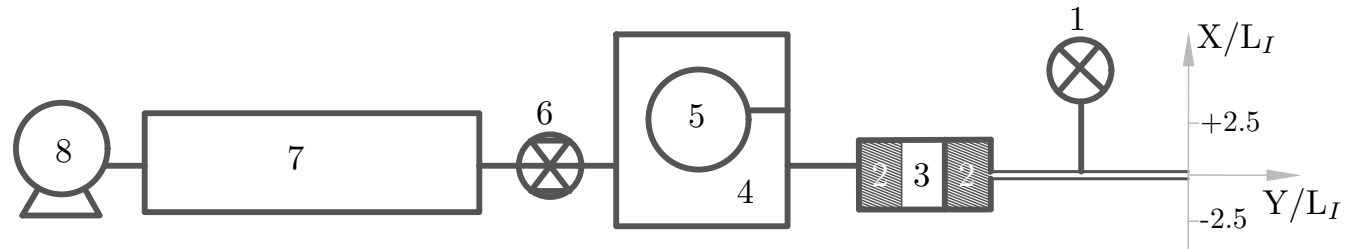

Figure 4: Sampling collection system used to measure gaseous species over $-2.5 \leq \mathrm{X} / \mathrm{L}_{I} \leq$ +2.5. 1) Pressure transducer; 2) Quartz wool; 3) Sodium sulphate; 4) Vacuum chamber; 5) Tedlar bag; 6) Vacuum regulator; 7) Vacuum volume; 8) Vacuum pump.

before the sample injection. The maximum cumulative error in the measured concentrations (based on the standard deviation) is estimated at $\pm 2.1 \%$ for major gaseous samples.

\subsubsection{PAH species}

The details of the PAH sampling and extraction process including a comprehensive uncertainty analyses were discussed by Shariatmadar et al. [3]. The sampling system, shown in Fig. 5, features dual-port dilution with preheated $\mathrm{N}_{2}$ at $523 \mathrm{~K}$ and PID controlled heated walls to minimise thermal gradients between the sample and probe walls, and therefore reduce PAH losses e.g. [71]. A temperature of $523 \mathrm{~K}$ was found optimal to minimise soot agglomeration as well as thermophoretic, adsorption and condensation losses within the system [72-74]. The probe-tip dilution ratio corresponds to the limit of minimum species losses during the collection process [3]. The sampling process suggests that transmission losses are relatively small using the respective optimum dilution ratio for each experimental condition as presented in the Supplemental Material.

The experimental repeatability, also presented in the Supplemental Material, is evaluated based on the standardised operational procedure that comprises 
analyses of the individual repeatability of sample collection, extraction and preparation. Figure 6(a) shows the evaluation of filter units assessed in preliminary studies. Filter unit-1 includes a quartz fiber filter ahead of quartz wool and a XAD adsorbent resin (Sigma Aldrich). Filter unit-2 consists a series of quartz wool and XAD resin. Direct analysis of the species concentration recorded with the quartz fibre filter in place leads to incorrect conclusions as it eliminates a significant fraction of the total signal measured using the mass spectrometer. For example, direct analysis of the species concentration shows a loss of $17 \%$ of the benzo(a)pyrene after a $120 \mathrm{~h}$ sonication time. The losses can stem either from a loss of particles or PAHs in the quartz fibre filter. The effect of centrifuging samples [75] is illustrated in Fig. 6(b) by $\mathrm{B}(\mathrm{a}) \mathrm{P}$ concentrations obtained at different experimental conditions. The composition of soot particles includes aromatic structures featuring stacked PAHs bound via (weak) van der Waals forces [76]. Resonance-stabilised radicals can deposit/infuse on soot particles either during sample collection or in the flame [14]. The infusion of PAHs onto particles is significantly increased at more highly sooting conditions as illustrated in Fig. 6(b) by the increase of $\mathrm{B}(\mathrm{a}) \mathrm{P}$ when reducing $\mathrm{a}_{T}=420 \mathrm{~s}^{-1}$ to $\mathrm{a}_{T}=255 \mathrm{~s}^{-1}$.

External and internal standard (reference) solutions are used to calibrate non-unit ion counts [77]. The former includes 17 different PAH compounds (Accustandard [DRH-006S]) and 29 refinery gas aromatics (Accustandard [M-GRA-CAL-R/IS-R-01]). The latter contains deuterated PAH standards (Accustandard [Z-014J-0.5X]). The internal standard solution is added to the liquid samples to account for routine variations in the response of the chromatographic system [78]. A Select-PAH column (CP7462) is used to 


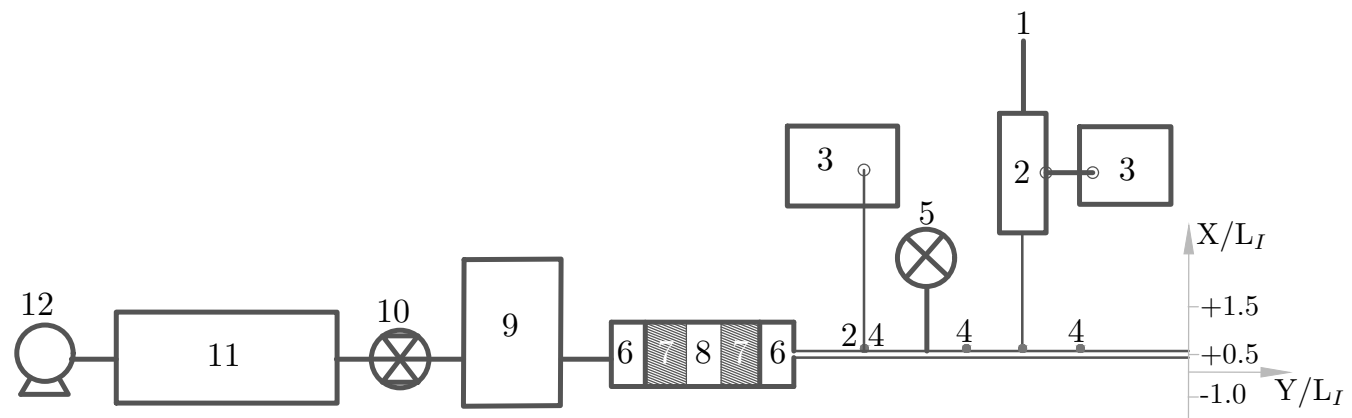

Figure 5: Sampling collection system used to measure PAH species over $-1.0 \leq \mathrm{X} / \mathrm{L}_{I} \leq$ +1.5. 1) Nitrogen dilution; 2) Heater; 3) PID controller; 4) Thermocouple; 5) Pressure transducer; 6) KF vacuum fitting; 7) Quartz wool; 8) XAD resin; 9) Vacuum chamber; 10) Vacuum regulator; 11) Vacuum volume; 12) Vacuum pump.

Table 2: GC-MS analysis conditions, where $\mathrm{P}_{i n}=34474 \mathrm{~Pa}$ and $\mathrm{T}_{i n}=573 \mathrm{~K}$ are the inlet pressure and temperature.

\begin{tabular}{l|c}
\hline Instrument & MSD (Agilent 5975C) \\
\hline Column & Select-PAH $(\mathrm{CP} 7462)$ \\
Carrier & Helium, constant flow $0.94 \mathrm{~mL} / \mathrm{min}$ \\
Oven & $343 \mathrm{~K}$ for $1 \mathrm{~min}, 40 \mathrm{~K} / \mathrm{min}$ to $453 \mathrm{~K}$, \\
program & $3 \mathrm{~K} / \mathrm{min}$ to $503 \mathrm{~K}, 1.5 \mathrm{~K} / \mathrm{min}$ to $508 \mathrm{~K}$, \\
& $10 \mathrm{~K} / \mathrm{min}$ to $553 \mathrm{~K}, 553 \mathrm{~K}$ for $5 \mathrm{~min}$, \\
& $5 \mathrm{~K} / \mathrm{min}$ to $571 \mathrm{~K}, 10 \mathrm{~K} / \mathrm{min}$ to $593 \mathrm{~K}$, \\
& $593 \mathrm{~K}$ for $5 \mathrm{~min}$. \\
\hline
\end{tabular}

quantify the PAH species. The GC conditions are summarised in Table 2. A selection of major identified compounds is listed in Table 3. The NIST Library and AMDIS software are utilised for the identification of species [79].

\subsection{Laminar flame calculations}

Laminar flame calculations were performed to support the interpretation of species growth and particle inception for various flame conditions. The inflow boundary conditions for the computational study matched the experimental data with identical reactant compositions and inlet temperatures. The computational domain also resembled that of the back-to-burnt exper- 

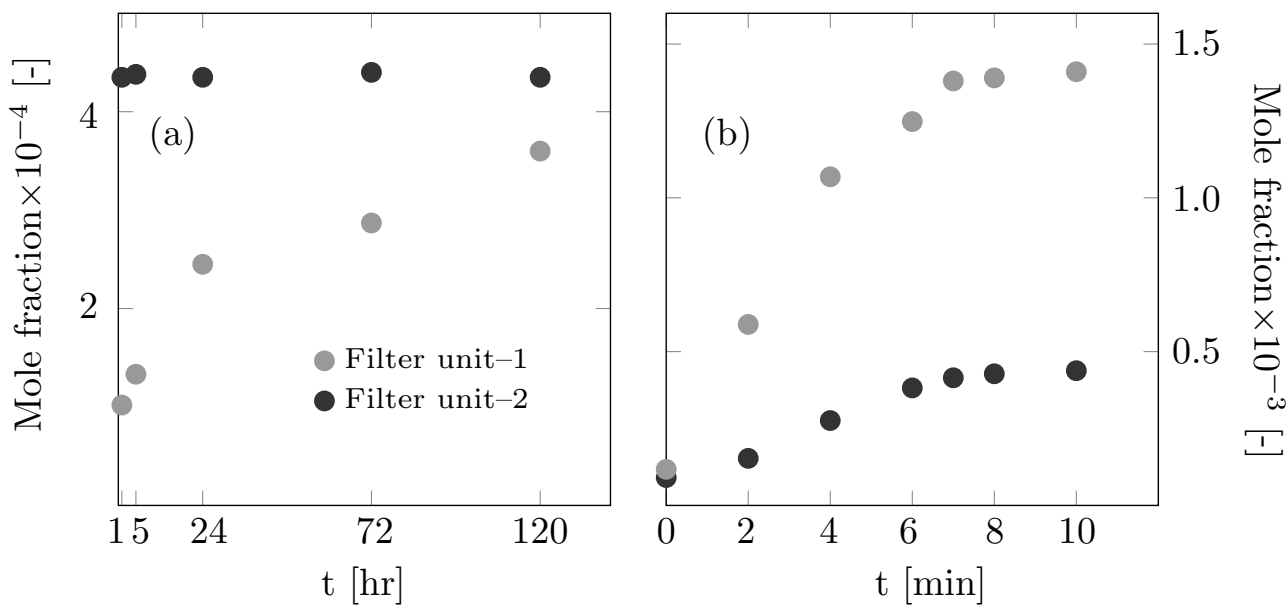

Figure 6: (a) Benzo(a)pyrene $(\mathrm{B}(\mathrm{a}) \mathrm{P})$ concentration over sonication intervals extracted from different filter units for the REF flame at the spatial location of $\mathrm{X} / \mathrm{L}_{I}=0.5$. (b) $\mathrm{B}(\mathrm{a}) \mathrm{P}$ concentration with respect to centrifuge time for $\mathrm{a}_{T}=420 \mathrm{~s}^{-1}$ (black) and $\mathrm{a}_{T}=$ $255 \mathrm{~s}^{-1}$ (gray) at a constant $\phi_{U N}=2.0$ and $\mathrm{T}_{H C P}=1500 \mathrm{~K}$. The results are consistent with the uncertainty analyses presented by Shariatmadar et al. [3].

imental setup with the exception that the flow is laminar. Hence, only the impact of bulk strain (not the turbulent strain) can be accounted for accurately in the simulations. However, approximate computations based on the addition of mean turbulent rate of strain were also performed and it must be noted that such computation are only indicative of the flame behaviour. The computational domain was resolved by 233 distributed cells with local refinement in the reaction zone providing a resolution of $36 \mu \mathrm{m}$. The detailed chemical mechanism featuring 358 species and 1789 reactions described by Lindstedt and Waldheim [34] was applied. The laminar flame data is used below to compare with experimental species profiles in mixture fraction space to illustrate the impact of the rate of strain. 
Table 3: The selection of identified species illustrated in Fig. 11. Bold texts are deuterated internal standard solutions. Gray numbers refer to species including isomers.

\begin{tabular}{l|l|l|l}
\hline ID & Name & ID & Name \\
\hline 1 & $\mathrm{~m} / \mathrm{z}=92$ & $\mathbf{d}$ & Phenanthrene-D10 \\
$\mathbf{a}$ & $\mathbf{1 , 4}-$ Dichlorobenzene & 15 & Phenanthrene \\
2 & $\mathrm{~m} / \mathrm{z}=132$ & 16 & Anthracene \\
3 & $\mathrm{~m} / \mathrm{z}=130$ & 17 & $\mathrm{~m} / \mathrm{z}=192$ \\
$\mathbf{b}$ & Naphthalene-D8 & 18 & $\mathrm{~m} / \mathrm{z}=206$ \\
4 & Naphthalene $[\mathrm{A} 2]$ & 19 & Pyrene isomer \\
5 & $\mathrm{~m} / \mathrm{z}=148$ & 20 & Pyrene $[\mathrm{A} 4]$ \\
6 & $\mathrm{~m} / \mathrm{z}=146$ & 21 & $\mathrm{~m} / \mathrm{z}=216$ \\
7 & $2-$ Methylnaphthalene $[2-\mathrm{MN}]$ & 22 & Benz(a)anthracene \\
8 & $1-$ Methylnaphthalene $[1-\mathrm{MN}]$ & $\mathbf{e}$ & Chrysene-D12 \\
9 & $1-\mathrm{MN}$ isomer & 23 & Chrysene \\
$\mathbf{1 0}$ & $\mathrm{m} / \mathrm{z}=156$ & $\mathbf{2 4}$ & $\mathrm{m} / \mathrm{z}=240$ \\
11 & $\mathrm{~m} / \mathrm{z}=154$ & 25 & Benzo(b)fluoranthene \\
12 & $\mathrm{~m} / \mathrm{z}=165$ & 26 & Benzo(k)fluoranthene \\
$\mathbf{c}$ & Acenaphthene-D10 & 27 & Benzo(a)pyrene (B(a)P) \\
13 & Fluorene & $\mathbf{f}$ & Perylene-D12 \\
14 & $\mathrm{~m} / \mathrm{z}=170$ & 28 & $\mathrm{~m} / \mathrm{z}=276$ \\
\hline
\end{tabular}

\section{Results and discussion}

\subsection{Results from non-intrusive measurements}

The strain and equivalence ratio impact on the PAH-PLIF and ELS signals are shown in Fig. 7 along the theoretical stagnation point streamline and normalised by the corresponding maximum in each subfigure. The extent of the turbulent reaction zone is $\sim 2.4 \mathrm{~L}_{I}$, consistent with Shariatmadar et al. [3] and Hampp et al. [53].

The peak ratios of the signals compared to the reference (REF) flame are presented in Table 4 . The results show that the occurrence of soot and PAH are strongly dependent on the properties of the flow field (e.g. the equivalence ratio and rate of strain) $[40,80]$. The relative increase in the soot concentration ratio (7.72) is higher than for gaseous PAH species (6.31) 

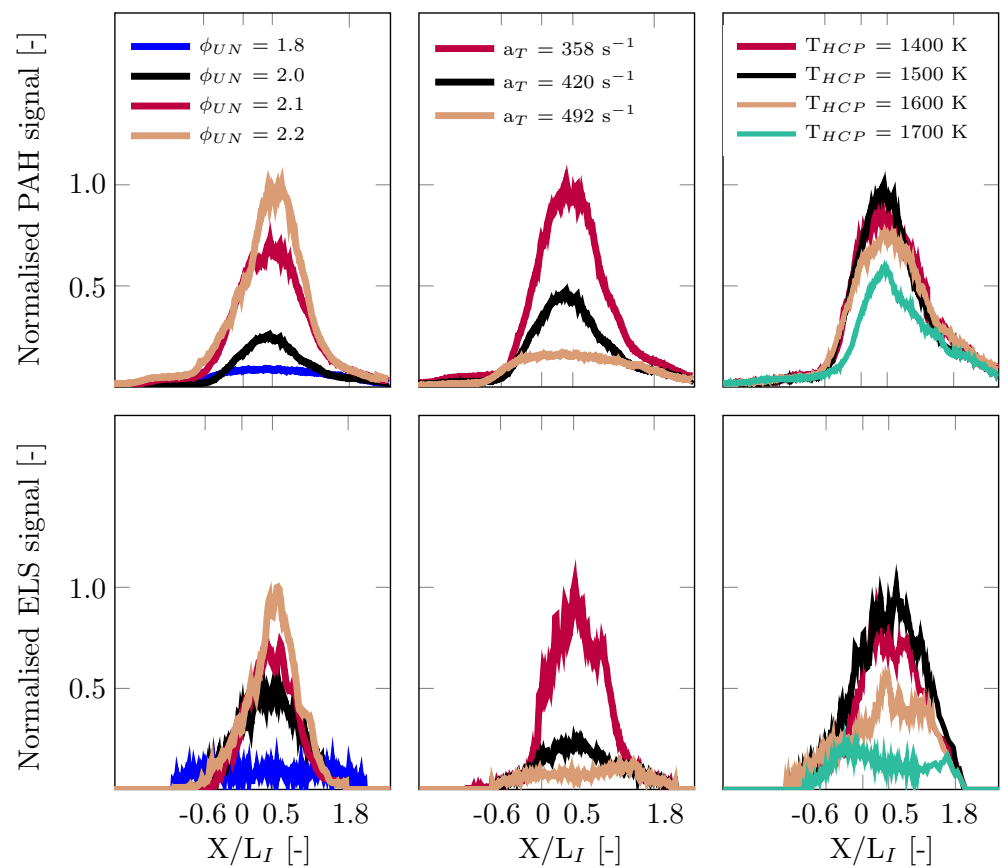

Figure 7: Normalised PAH-PLIF (top) and ELS (bottom) signals across the turbulent reaction zone for various equivalence ratios (left), total rates of strain (middle) and burnt gas temperature (right). The relatively high laser fluence at $355 \mathrm{~nm}$ suggests that soot particle incandescence contributes to the PAH - LIF signal [57]. Thus, this data is likely to include contributions from PAHs infused on soot particles as well as gaseous species. Left column : $1.8 \leq \phi_{U N} \leq 2.2, \mathrm{a}_{T}=420 \mathrm{~s}^{-1}$ and $\mathrm{T}_{H C P}=1500 \mathrm{~K}$; Middle column $: \phi_{U N}=2.0,358 \leq \mathrm{a}_{T}\left[\mathrm{~s}^{-1}\right] \leq 492$ and $\mathrm{T}_{H C P}=1500 \mathrm{~K}$; Right column $: \phi_{U N}=2.0$, $\mathrm{a}_{T}=420 \mathrm{~s}^{-1}, 1400 \leq \mathrm{T}_{H C P}[\mathrm{~K}] \leq 1700$. Signals are normalised by the corresponding maximum value among the cases presented in each subfigure. The profiles are taken at the theoretical stagnation point streamline, i.e. $\mathrm{Y} / \mathrm{L}_{I}=0$.

although soot incandescence is also contributing to the PAH signal as the rate of strain rate is reduced from $a_{T}=492 \mathrm{~s}^{-1}$ to $a_{T}=358 \mathrm{~s}^{-1}$. Overall, the results indicate that the both soot and PAH formation are exceptionally sensitive to the rate of strain and by implication to the local flow field conditions. The results further indicate that soot, in particular, can grow rapidly in regions of low rates of strain [37, 81-83]. By contrast, PAH concentrations are comparatively strong influenced by the equivalence ratio with an increase 
of a factor of 4 compared to 1.92 for soot in the range $2.0 \leq \phi_{U N} \leq 2.2$. The two values are inevitably linked due to PAH adsorption on soot particles.

The PAH concentrations are comparatively insensitive to the lower nozzle HCP temperature as shown in Fig. 7. There is a decrease in PAH from the reference value to 0.88 when the temperature is reduced from 1500 to $1400 \mathrm{~K}$. A decrease is also noted as the temperature is raised to 1600 and $1700 \mathrm{~K}$. The trend correlates with the ELS signal which implies a high level of competition between soot formation and oxidation reactions with soot oxidation starting to take precedent at temperatures higher than $1600 \mathrm{~K}$. The trend is stronger for soot with a drop of the normalised peak to 0.23 compared to 0.59 for PAH-PLIF and even more so considering a soot incandescence contribution to the PAH signal. The decreased thermodynamic stability of soot precursors and reduced surface reactivity at higher temperatures are expected to decrease soot formation as suggested by Frenklach et al. [84] and will also promote soot oxidation. Beyond a critical value, determined by the balance between formation and oxidation reactions, an increase in the hot combustion temperature $\left(\mathrm{T}_{H C P}\right)$ will favour $\mathrm{PAH}$ and soot oxidation reactions. Based on laminar flame calculations, the peak reaction zone temperature increases from $1412 \mathrm{~K}$ to $1795 \mathrm{~K}$ with an increase of $\mathrm{T}_{H C P}$ from $1400 \mathrm{~K}$ to $1700 \mathrm{~K}$ at a constant $\mathrm{a}_{T}=420 \mathrm{~s}^{-1}$ and $\phi_{U N}=2.0$ (see Fig. 4(b) in Supplemental Material). The resulting gradual increase in temperature leads to a modest reduction in the normalised PAH-LIF peak value at an unchanged location of $\mathrm{X} / \mathrm{L}_{I}=0.5$. At the highest $\mathrm{HCP}$ temperature investigated, it can be noted that the peak of the substantially reduced ELS signal shifts approximately $3 / 4 \mathrm{~L}_{I}$ towards the HCP stream suggesting that soot is more likely to prevail 
Table 4: Peak PAH-PLIF and ELS values at various experimental conditions normalised relative to the reference $(\mathrm{REF})$ flame $\left(\phi_{U N}=2.0, a_{T}=420 \mathrm{~s}^{-1}\right.$ and $\left.T_{H C P}=1500 \mathrm{~K}\right)$. The relatively high laser fluence at $355 \mathrm{~nm}$ suggests that soot particle incandescence contributes to the PAH - LIF signal [57]. Thus, this data is likely to include contributions from PAHs infused on soot particles as well as gaseous species.

\begin{tabular}{c|c|c}
\hline Case & PAH-PLIF & ELS \\
\hline$\phi_{U N}=1.80$ & 0.36 & 0.21 \\
$\phi_{U N}=2.00$ & 1.00 & 1.00 \\
$\phi_{U N}=2.10$ & 2.80 & 1.38 \\
$\phi_{U N}=2.20$ & 4.00 & 1.92 \\
\hline \hline$a_{T}=358 \mathrm{~s}^{-1}$ & 2.27 & 4.17 \\
$a_{T}=420 \mathrm{~s}^{-1}$ & 1.00 & 1.00 \\
$a_{T}=492 \mathrm{~s}^{-1}$ & 0.36 & 0.54 \\
\hline \hline$T_{H C P}=1400 \mathrm{~K}$ & 0.88 & 0.90 \\
$T_{H C P}=1500 \mathrm{~K}$ & 1.00 & 1.00 \\
$T_{H C P}=1600 \mathrm{~K}$ & 0.77 & 0.57 \\
$T_{H C P}=1700 \mathrm{~K}$ & 0.59 & 0.23 \\
\hline
\end{tabular}

371

in the reaction products.

The current laser diagnostic measurements cannot (i) distinguish between different PAH species or (ii) elucidate the transition from molecular to solid nanostructures and soot formation. Accordingly, interactions between PAHs and particles cannot be precisely distinguished [85]. ELS can also be prone to errors including interference by absorbing gas-phase species [76]. A probe sampling method is accordingly utilised to provide information on the flame structure and the spatial distribution of PAHs contributing to adsorption and primary particle formation. 


\subsection{Flame structure and major gaseous species}

\subsubsection{Sampling probe}

The overall flame structure was investigated by obtaining major species concentrations at 11 axial sample positions along the stagnation point streamline (i.e. X direction). The measurement intervals were approximately half an integral length scale of turbulence $\left(0.5 \mathrm{~L}_{I}\right)$. The measured mole fraction of major gaseous species $\left(\mathrm{C}_{2} \mathrm{H}_{4}, \mathrm{O}_{2}, \mathrm{CO}, \mathrm{CO}_{2}, \mathrm{CH}_{4}, \mathrm{C}_{2} \mathrm{H}_{2}, \mathrm{C}_{3} \mathrm{H}_{6}\right.$ and $\left.\mathrm{C}_{3} \mathrm{H}_{8}\right)$ are shown in Figs. 8 and 9. The experimentally determined major species mole fractions for all cases are also given in tabular form in the Supplemental Material.

The peak ratios of the measured mean concentrations of stable hydrocarbon species are presented in Table 5. For the sooting flames, the increasing amount of acetylene mirrors the increase in PAH concentrations to some extent. The PAH-PLIF signal increases by a factor of 4 from $\phi_{U N}=2.0$ to 2.2 (see Table 4), while the acetylene concentration increases by a factor of 2.25. The corresponding increase in the ELS signal is a factor of 1.92, close to the increase in the acetylene concentration. The same trend is observed for major hydrocarbon species including $\mathrm{CH}_{4}, \mathrm{C}_{2} \mathrm{H}_{2}, \mathrm{C}_{3} \mathrm{H}_{6}$ and $\mathrm{C}_{3} \mathrm{H}_{8}$ as the stoichiometry is varied from $\phi_{U N}=1.8$ to $\phi_{U N}=2.2$. It can be noted that the increase in the acetylene concentration with stoichiometry is less than for the $\mathrm{C}_{3}$ species. This may be due to depletion caused by acetylene addition to soot via HACA type mechanisms (c.f. [86]). The current data also shows that the rate of strain has a very significant impact with $a_{T}=610 \mathrm{~s}^{-1}$ resulting in a decrease of $60 \%$ for propene and $55 \%$ for propane compared to the reference flame. The reduction is due to both the flame structure 
Table 5: The peak ratio of major gaseous species. The peaks are normalised relative to the reference $(\mathrm{REF})$ flame $\left(\phi_{U N}=2.0, a_{T}=420 \mathrm{~s}^{-1}\right.$ and $\left.T_{H C P}=1500 \mathrm{~K}\right)$. The two last columns indicate the impact of a rate of strain variation for the $\phi_{U N}=2.0$ flame.

\begin{tabular}{c|c|c|c|c}
\hline Species & $\phi_{U N}=1.80$ & $\phi_{U N}=2.20$ & $a_{T}=255$ & $a_{T}=610$ \\
\hline $\mathrm{CH}_{4}$ & 0.37 & 1.60 & 2.28 & 0.43 \\
$\mathrm{C}_{2} \mathrm{H}_{2}$ & 0.46 & 2.25 & 3.00 & 0.57 \\
$\mathrm{C}_{3} \mathrm{H}_{6}$ & 0.20 & 2.46 & 3.00 & 0.40 \\
$\mathrm{C}_{3} \mathrm{H}_{8}$ & 0.34 & 2.53 & 3.20 & 0.45 \\
\hline
\end{tabular}

and turbulence effects [87] with the latter leading to a Damköhler (Da) number dependent species scattering within the reaction zone [88]. Thus, the interface thicknesses can become governed by the turbulent transport and mixing suggesting a potentially significant impact of turbulence and the rate of strain on the species distribution within the flame structure. On the other hand, the mean concentration of species rises at lower strain rates and higher equivalence rates [89]. The increase in concentrations of intermediate species at at lower rates of strain $\left(a_{T}=255 \mathrm{~s}^{-1}\right)$ further indicates complex turbulence-chemistry interactions.

\subsubsection{Mixture fraction and chemical species correlations}

The experimental determination of major carbon containing species permit the tentative evaluation of the carbon based mixture fraction $\left(f_{c}\right)$. The carbon based mixture fraction is calculated from seven carbon containing species $\left(\mathrm{CO}, \mathrm{CO}_{2}, \mathrm{CH}_{4}, \mathrm{C}_{2} \mathrm{H}_{2}, \mathrm{C}_{2} \mathrm{H}_{4}, \mathrm{C}_{3} \mathrm{H}_{6}\right.$ and $\left.\mathrm{C}_{3} \mathrm{H}_{8}\right)$ for both experimental data and the laminar flame computations on a dry basis (omitting the water concentrations). The use of an equal diffusivity approximation or the inclusion of all carbon containing species (including soot sections) in the 

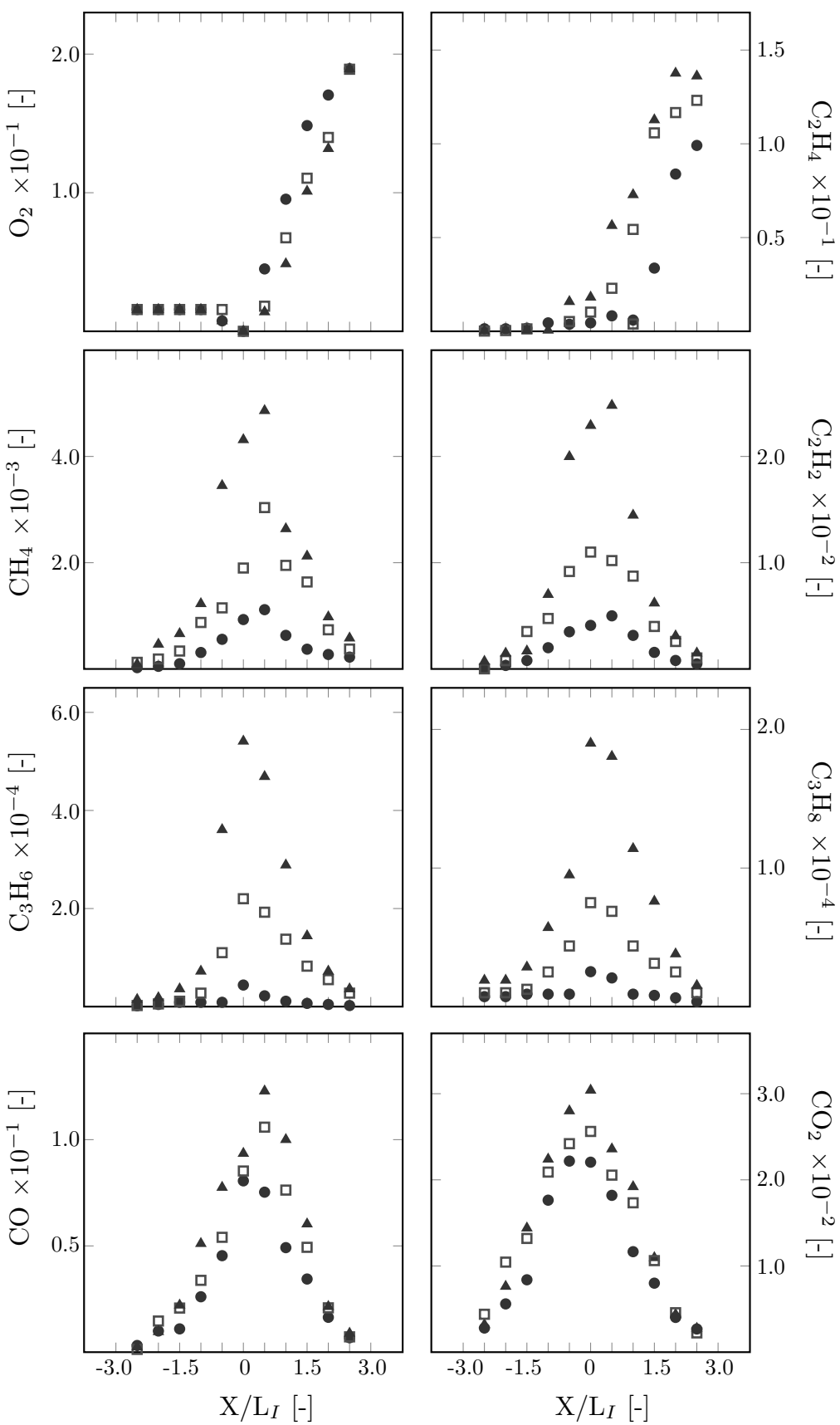

Figure 8: The impact of equivalence ratio on mole fractions of major gaseous species at different spatial location for $a_{T}=420 \mathrm{~s}^{-1}$ and $T_{H C P}=1500 \mathrm{~K}$. Circle $-\phi_{U N}=1.8$; Square $-\phi_{U N}=2.0$; Triangle $-\phi_{U N}=2.2$. The filter unit, containing quartz wool and sodium sulphate, is used to remove water vapour from the gaseous sample. $\mathrm{X} / \mathrm{L}_{I}>0$ is towards reactants and $\mathrm{X} / \mathrm{L}_{I}<0$ towards the hot combustion products. 

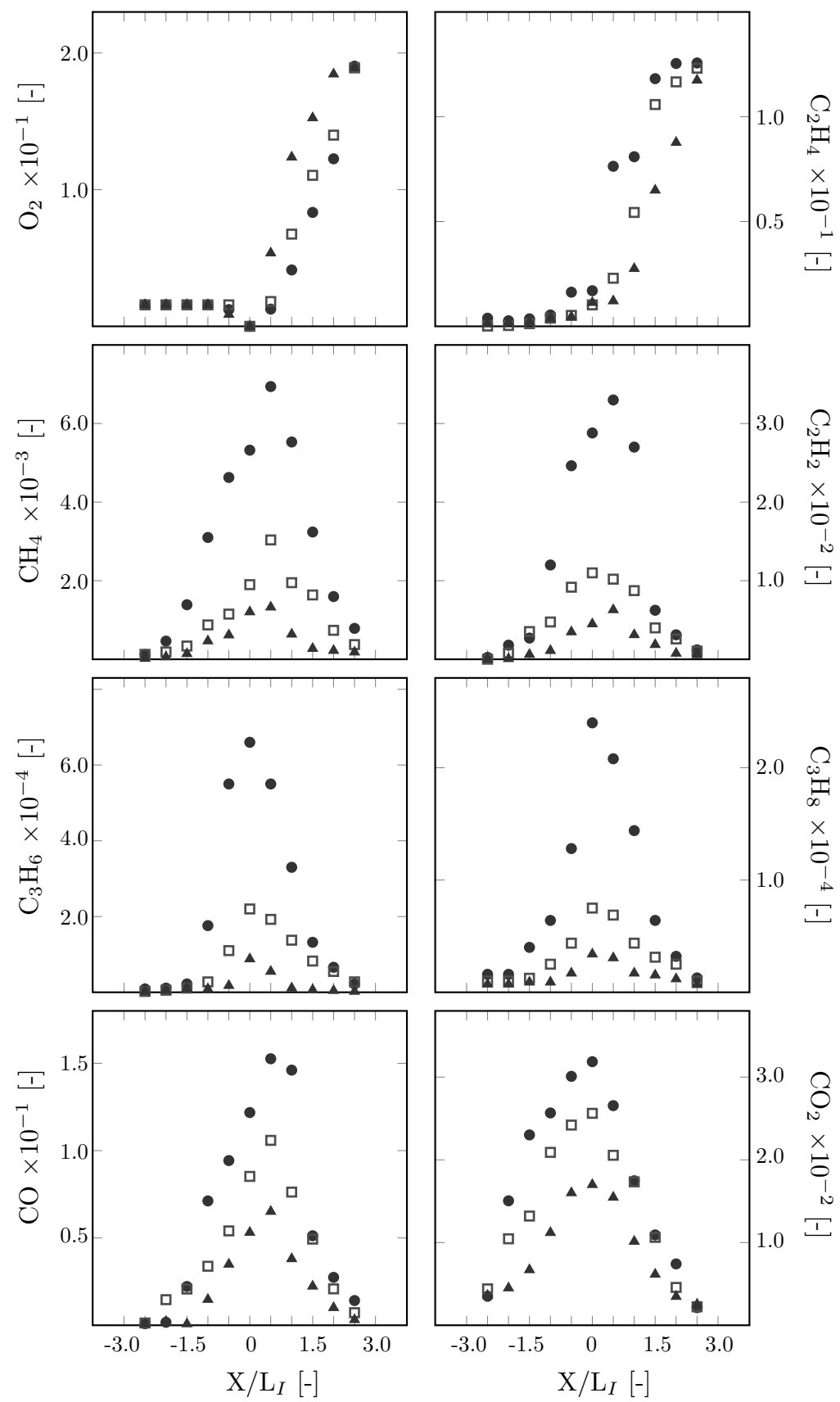

Figure 9: The impact of strain rate on mole fractions of major gaseous species at different spatial location for $\phi_{U N}=2.0$ and $T_{H C P}=1500 \mathrm{~K}$. Circle $-a_{T}=225 \mathrm{~s}^{-1}$; Square $a_{T}=420 \mathrm{~s}^{-1}$; Triangle $-a_{T}=610 \mathrm{~s}^{-1}$. The filter unit, containing quartz wool and sodium sulphate, is used to remove water vapour from the gaseous sample. $\mathrm{X} / \mathrm{L}_{I}>0$ is towards reactants and $\mathrm{X} / \mathrm{L}_{I}<0$ towards the hot combustion products. 
computations does not alter results appreciably.

$$
\mathrm{f}_{c}=\frac{\sum_{k=1}^{n s p} n_{C_{k}} X_{k}}{\sum_{k=1}^{n s p} X_{k} M_{k}} \cdot\left(\frac{n_{C_{F}}}{M_{F}}\right)^{-1}=\frac{M_{F}}{M} \frac{1}{n_{C_{F}}} \sum_{k=1}^{n s p} n_{C_{k}} X_{k}
$$

where $\mathrm{n}_{C_{k}}$ denotes the number of carbon atoms in species $\mathrm{k}$ and $\mathrm{n}_{C_{F}}$ the number of carbon atoms in the fuel, and $\mathrm{M}$ is the mean molecular weight. Results from laminar flame computations with the approximately limiting rates of strain of $\mathrm{a}_{b}=120 \mathrm{~s}^{-1}$ and $\mathrm{a}_{T}=420 \mathrm{~s}^{-1}$ are shown in Fig. 10 for the REF flame. The latter features an approximate total rate of strain of $420 \mathrm{~s}^{-1}$, a stoichiometry $\phi_{U N}=2.0$, and a counterflow $\mathrm{T}_{H C P}=1500 \mathrm{~K}$. As shown, the mole fractions of major species are mostly bounded by the flamelet computations. However, the strong impact of the rate of strain, particularly on intermediate hydrocarbons, is clearly illustrated. The mixture fractions and chemical species are presented for all other experimental conditions in the Supplemental Material.

\subsection{Distribution of PAHs through the flame brush}

Direct probe sampling from the flame (online sampling) leads to PAH losses within the extraction line and the filter unit and neglects PAH adsorption onto soot. Samples should also include internal standard solutions to account for routine variations in the response of the chromatographic system, which is not applicable to online sampling. Therefore, optimum sampling conditions were established to minimise experimental uncertainties as outlined in the SMM. The Select-PAH column is used to quantify the major 

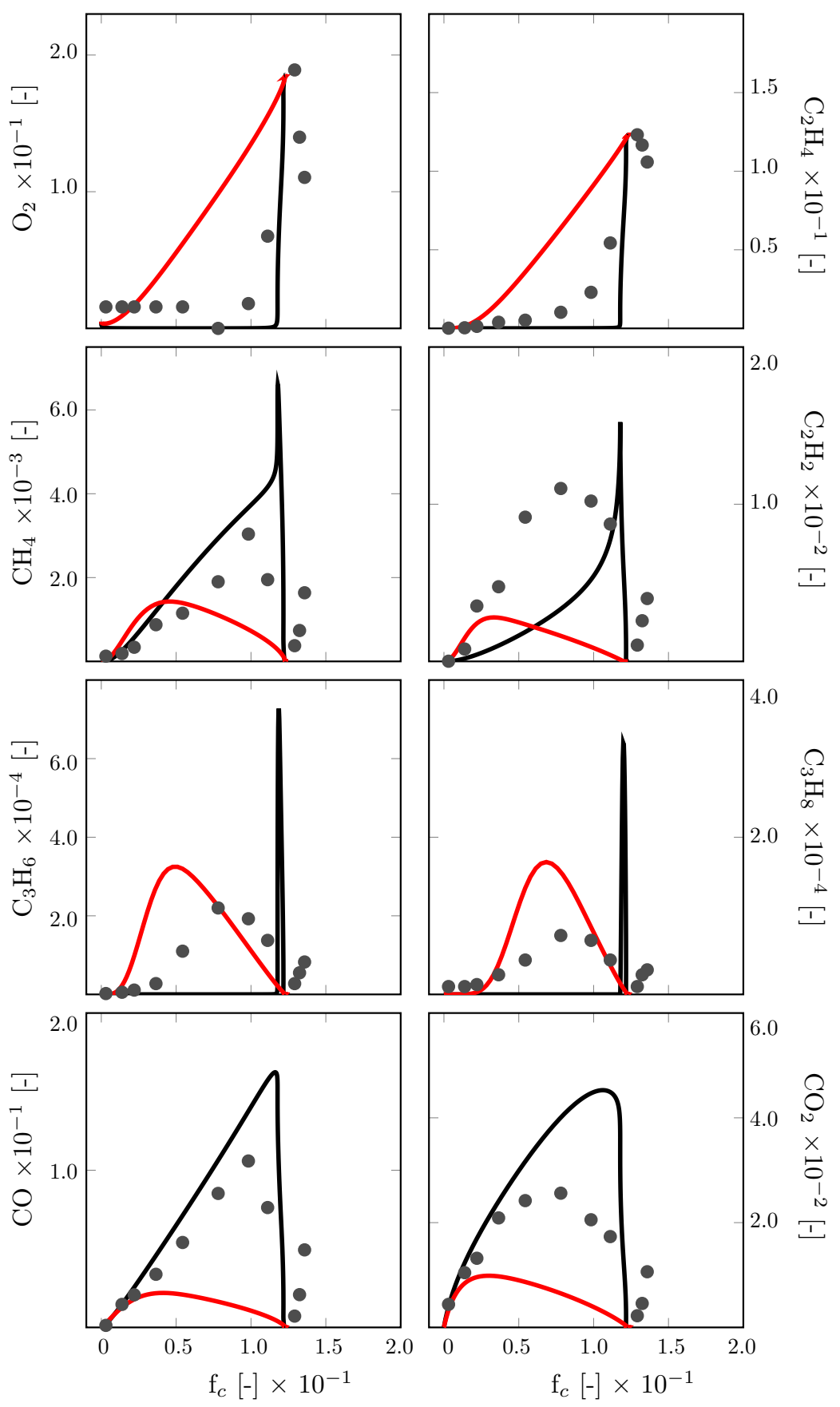

Figure 10: Species profile versus mixture fraction for $\phi_{U N}=2.0$ at rates of strain of $a_{T}=420 \mathrm{~s}^{-1}$ (red) and $a_{b}=120 \mathrm{~s}^{-1}$ (black) and a burnt gas temperature of $\mathrm{T}_{H C P}=$ 1500 K. Experiments indicated by circles. 
PAH species (see Table 3). As shown in the mass spectrum (Fig. 11), the mass distribution of PAH species covers the interval of $92 \leq \mathrm{m} / \mathrm{z}[\mathrm{u}] \leq 300$. Accordingly, the concentrations provided in Figs. 12 and 14 correspond to the mole fractions of PAH species $(92 \leq \mathrm{m} / \mathrm{z}[\mathrm{u}] \leq 300)$ in the analysed liquid sample including the solvent (DCM) contribution. A direct comparison of in situ techniques and probe sampling is challenging. On the one hand, laser diagnostics cannot precisely quantify the infusion level of resonancestabilised radicals on soot particles in the flame. The quantification of PAH species using LIF is a challenging task as PAHs species contain a mixture of distinct functional groups with broad spectra. The spectra of such species can overlap with each other. On the other hand, GC-MS can present the mass spectrum of species up to $\mathrm{m} / \mathrm{z}=300 \mathrm{amu}$. The given data cannot include all PAHs.

Mass spectra (MS) extracted from the lower and upper limit rates of strain $\left(a_{T}=225\right.$ and $\left.610 \mathrm{~s}^{-1}\right)$ are shown in Fig. 11. Samples of mass spectra extracted at different spatial locations are also presented in Supplemental Material for the various experimental conditions. The results cover four intervals of the retention time (RT). The letters (a, b, c, d, e, f) refer to the internal standard solution (ISD) used to correct the MS response. The major species determined here have also been observed experimentally in other studies $[13,90,91]$. The MS results present known species where these can be identified and confirmed using external standard calibration, NIST library and AMDIS software. In other cases, the $\mathrm{m} / \mathrm{z}$ ratio is presented as shown in Table 3 . The presence of two peak sequences is noticeable among the species shown in the mass spectra. The first sequence appears with $24 \mathrm{~m} / \mathrm{z}$ 
units gap, which supports the role of $\mathrm{C}_{2}$ addition via HACA style sequences followed by dehydrogenation. The growth of PAHs is further consistent with the addition of $\mathrm{CH}_{2}$ (methylene) and $\mathrm{CH}_{3}$ (followed by dehydrogenation) as shown by the $14 \mathrm{~m} / \mathrm{z}$ gaps between PAH species [92]. The formation of a five-member rings can result from $\mathrm{C}_{2} \mathrm{H}_{2}$ addition, intramolecular hydrogen migration, $\mathrm{CH}_{2}$ addition, and cyclization with $\mathrm{H}$ elimination [93].

The mass spectra show that concentrations of comparatively heavy PAHs (i.e. $\mathrm{B}(\mathrm{a}) \mathrm{P}$ and $\mathrm{m} / \mathrm{z}=276$ ) can build up ahead of light species [14]. However, the importance of lighter molecules (e.g. 1-methyl naphthalene (1-MN) and $\mathrm{m} / \mathrm{z}=154$ ) should not be neglected. For instance, $1-\mathrm{MN}$ is a comparatively stable methyl-substituted two-ringed PAH. Schulz et al. [16] and Commodo et al. [17] suggest that methyl group substitutions make an important contribution to soot formation. As shown in our study, $1-\mathrm{MN}$ is one of the major PAHs detected in the current turbulent flames. By contrast, 2-MN is present in smaller quantities suggesting a comparatively modest contribution to soot formation. Johansson et al. [94] suggest that it is crucial to consider the contributions made by all $\mathrm{m} / \mathrm{z}=154$ isomers to the nucleation process. Reactions featuring PAHs also provide a route for mass growth [32] and structures involving $\mathrm{C}_{5}$ rings can appear in quantities similar to, or exceeding, those based on $\mathrm{C}_{6}$ rings [95].

The impact of the equivalence ratio and rate of strain on the spatial distribution of PAHs is shown in Figs. 12 and 14. The experimentally determined PAH species mole fractions for all cases are also given in tabular form in the Supplemental Material. It is important to note that the prevalence shown includes the solvent and correspond to the amounts present in the 

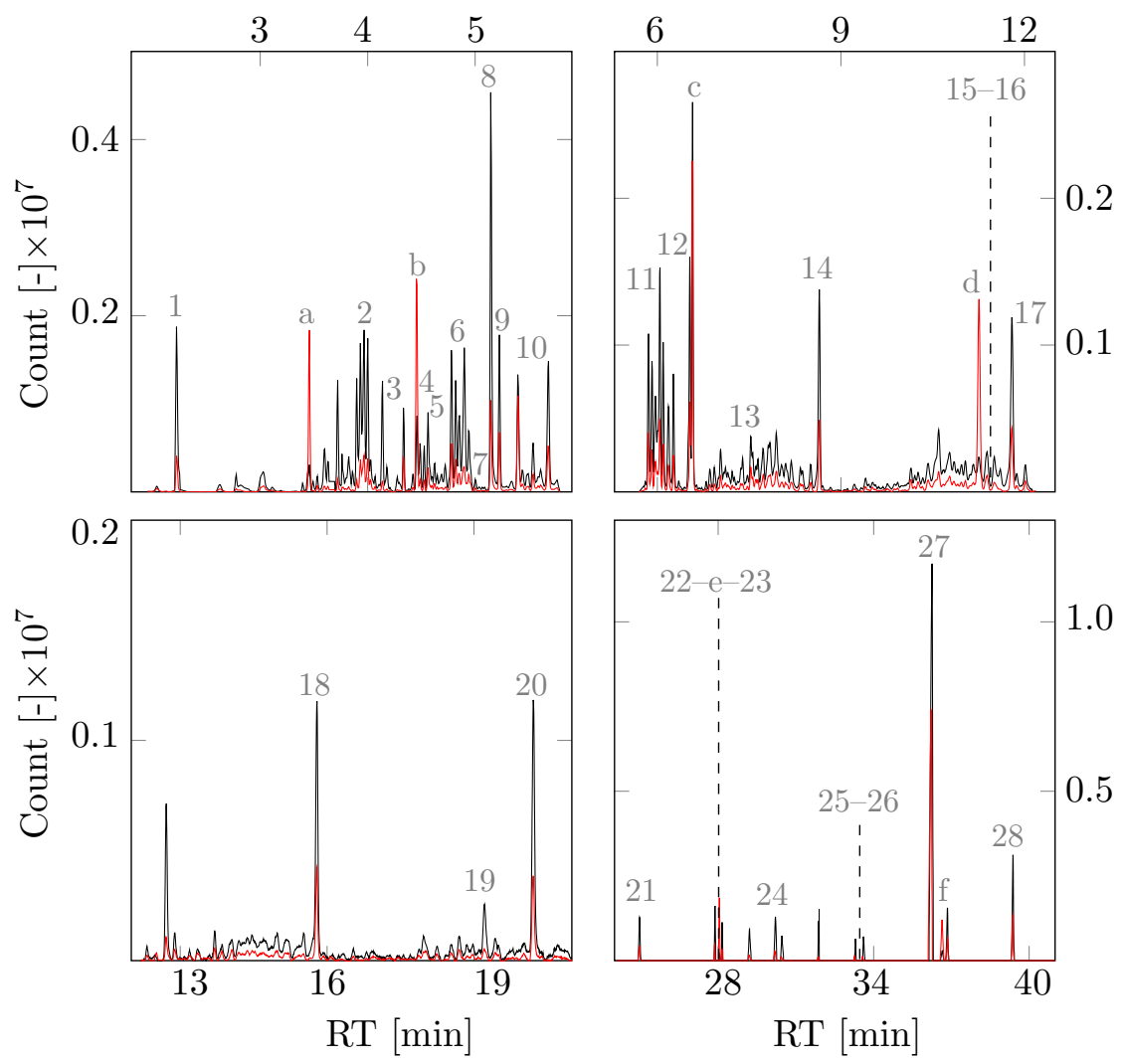

Figure 11: Mass spectra extracted from low $\left(a_{T}=225 \mathrm{~s}^{-1}\right.$ - black $)$ and high rates of strain $\left(a_{T}=610 \mathrm{~s}^{-1}-\right.$ red $)$ showing the distribution of major PAH species. The mass spectra were extracted from a spatial location of $\mathrm{X} / \mathrm{L}_{I}=0.5$ at a constant equivalence ratio of $\phi_{U N}=2.0$ and burnt gas temperature of $\mathrm{T}_{H C P}=1500 \mathrm{~K}$. The peak labels correspond to a list presented in Table 3 .

treated sample collected over approximately 10,000 integral time scales of turbulence. The consumption of PAHs is aided by the elevated temperatures found in the nearly sooting flame $\left(\phi_{U N}=1.80\right.$ and $\left.a_{T}=610 \mathrm{~s}^{-1}\right)$ leading to increased oxidation. By contrast, flames at low rates of strain $\left(a_{T}=225 \mathrm{~s}^{-1}\right)$ or high equivalence ratios $\left(\phi_{U N}=2.20\right)$ support the formation and survival of PAHs [96].

As shown above, through the use of PAH-PLIF and ELS, the rate of 

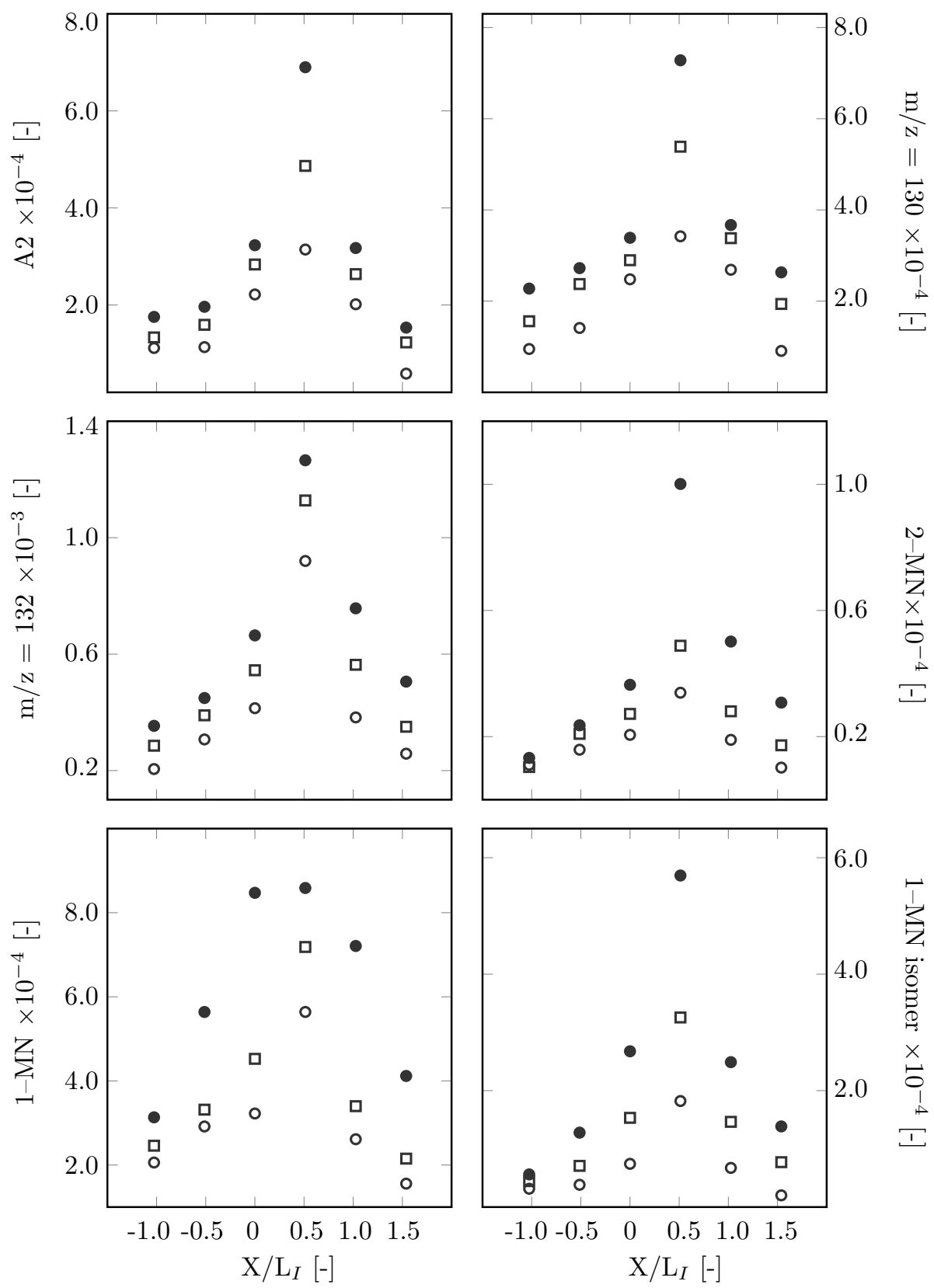

Figure 12: The impact of equivalence ratio on the extracted distribution of PAHs along reaction zone layer at a constant $a_{T}=420 \mathrm{~s}^{-1}$ and $T_{H C P}=1500 \mathrm{~K}$. The concentrations correspond to the mole fractions of PAH $(92 \leq \mathrm{m} / \mathrm{z}[\mathrm{u}] \leq 300)$ in the analysed liquid sample including the solvent $(\mathrm{DCM})$ contribution. Open circle $-\phi_{U N}=1.8$; Square $\phi_{U N}=2.0 ;$ Filled circle $-\phi_{U N}=2.2 . \quad \mathrm{X} / \mathrm{L}_{I}>0$ is towards reactants and $\mathrm{X} / \mathrm{L}_{I}<0$ towards the hot combustion products. 

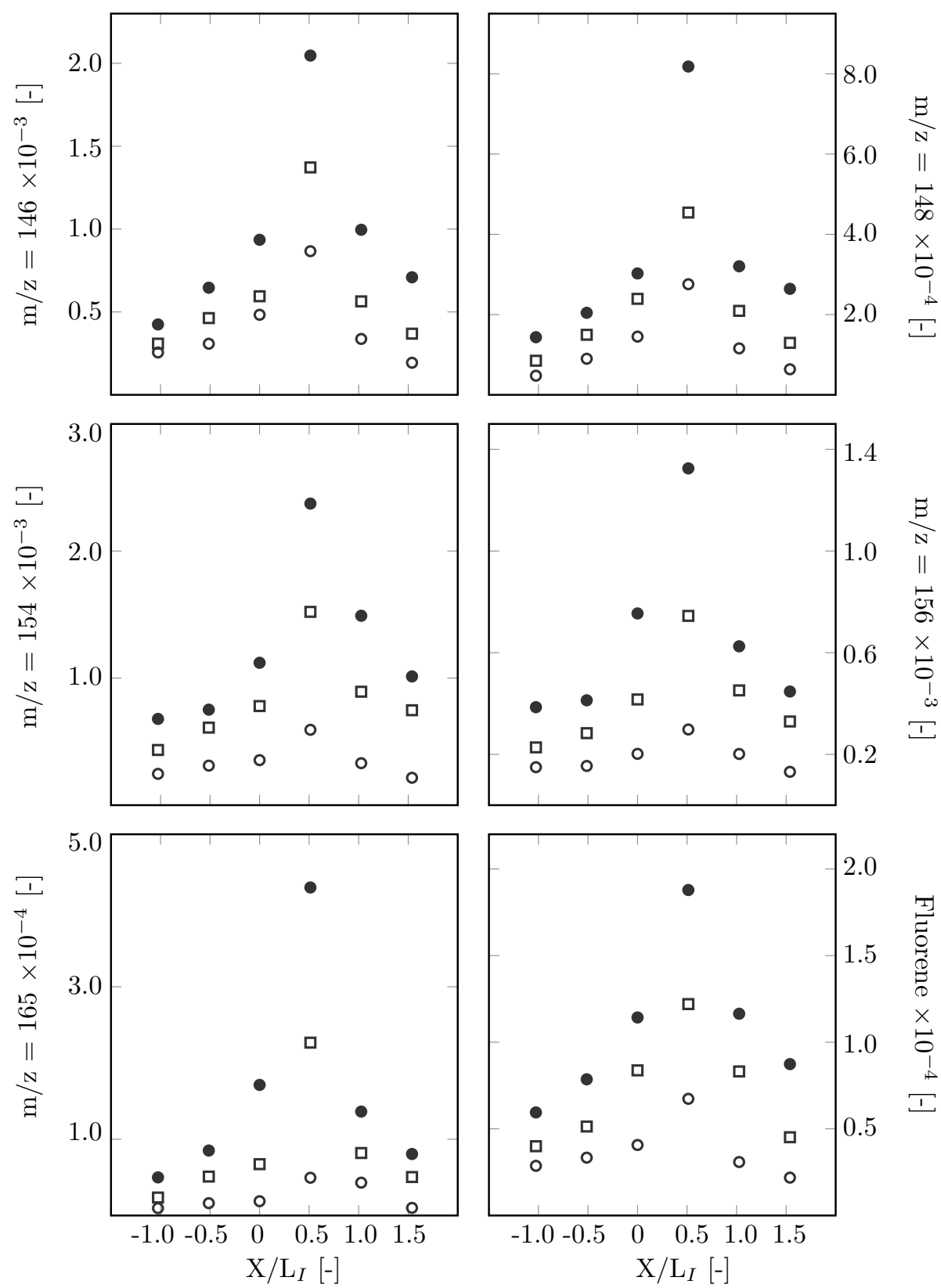

Figure 12 (Cont.): The impact of equivalence ratio on the extracted distribution of PAHs along reaction zone layer at a constant $a_{T}=420 \mathrm{~s}^{-1}$ and $T_{H C P}=1500 \mathrm{~K}$. The concentrations correspond to the mole fractions of PAH $(92 \leq \mathrm{m} / \mathrm{z}[\mathrm{u}] \leq 300)$ in the analysed liquid sample including the solvent $(\mathrm{DCM})$ contribution. Open circle $-\phi_{U N}=1.8$; Square $-\phi_{U N}=2.0 ;$ Filled circle $-\phi_{U N}=2.2 . \mathrm{X} / \mathrm{L}_{I}>0$ is towards reactants and $\mathrm{X} / \mathrm{L}_{I}<0$ towards the hot combustion products. 

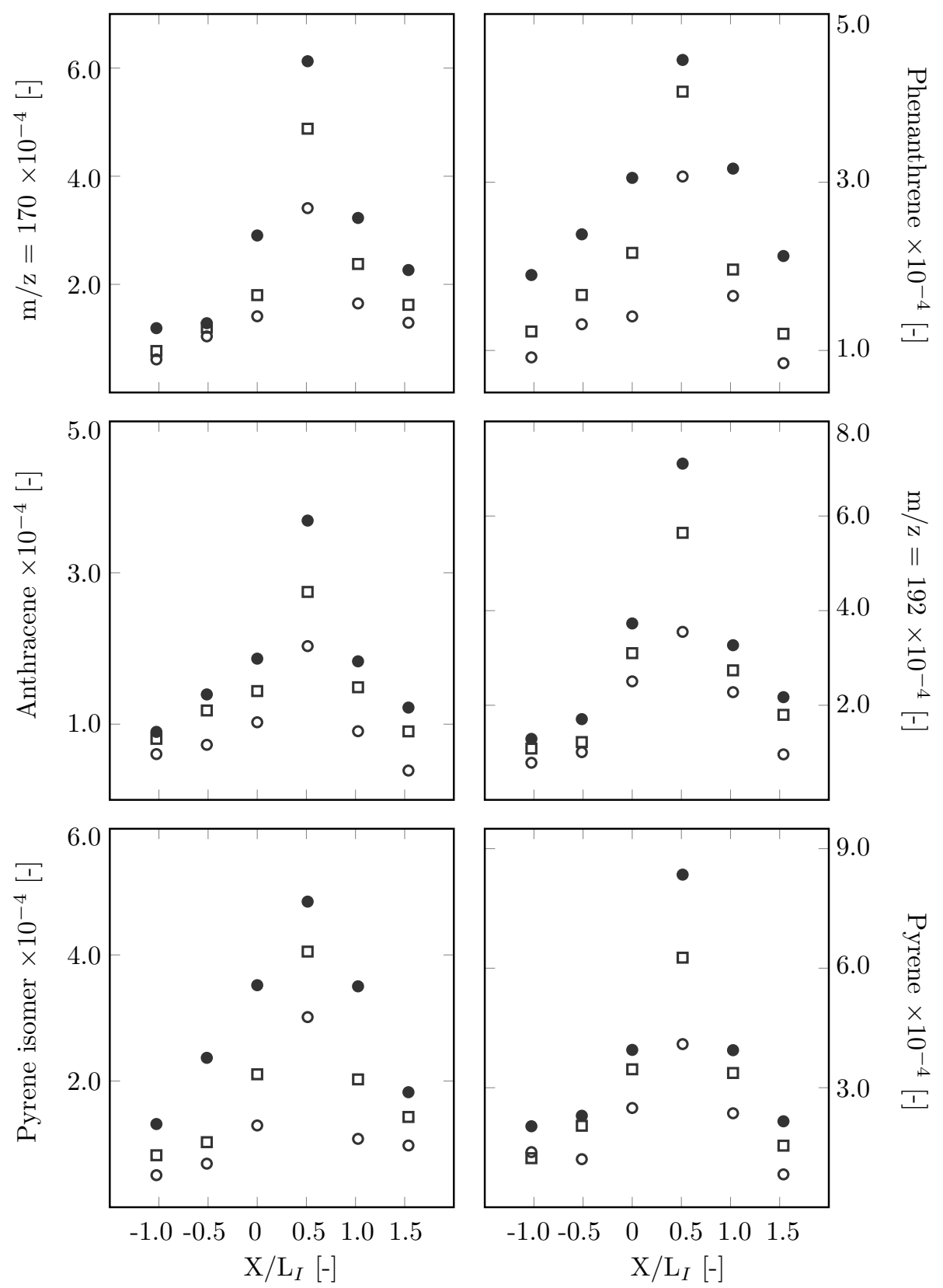

Figure 12 (Cont.): The impact of equivalence ratio on the extracted distribution of PAHs along reaction zone layer at a constant $a_{T}=420 \mathrm{~s}^{-1}$ and $T_{H C P}=1500 \mathrm{~K}$. The concentrations correspond to the mole fractions of PAH $(92 \leq \mathrm{m} / \mathrm{z}[\mathrm{u}] \leq 300)$ in the analysed liquid sample including the solvent $(\mathrm{DCM})$ contribution. Open circle $-\phi_{U N}=1.8$; Square $-\phi_{U N}=2.0 ;$ Filled circle $-\phi_{U N}=2.2 . \mathrm{X} / \mathrm{L}_{I}>0$ is towards reactants and $\mathrm{X} / \mathrm{L}_{I}<0$ towards the hot combustion products. 

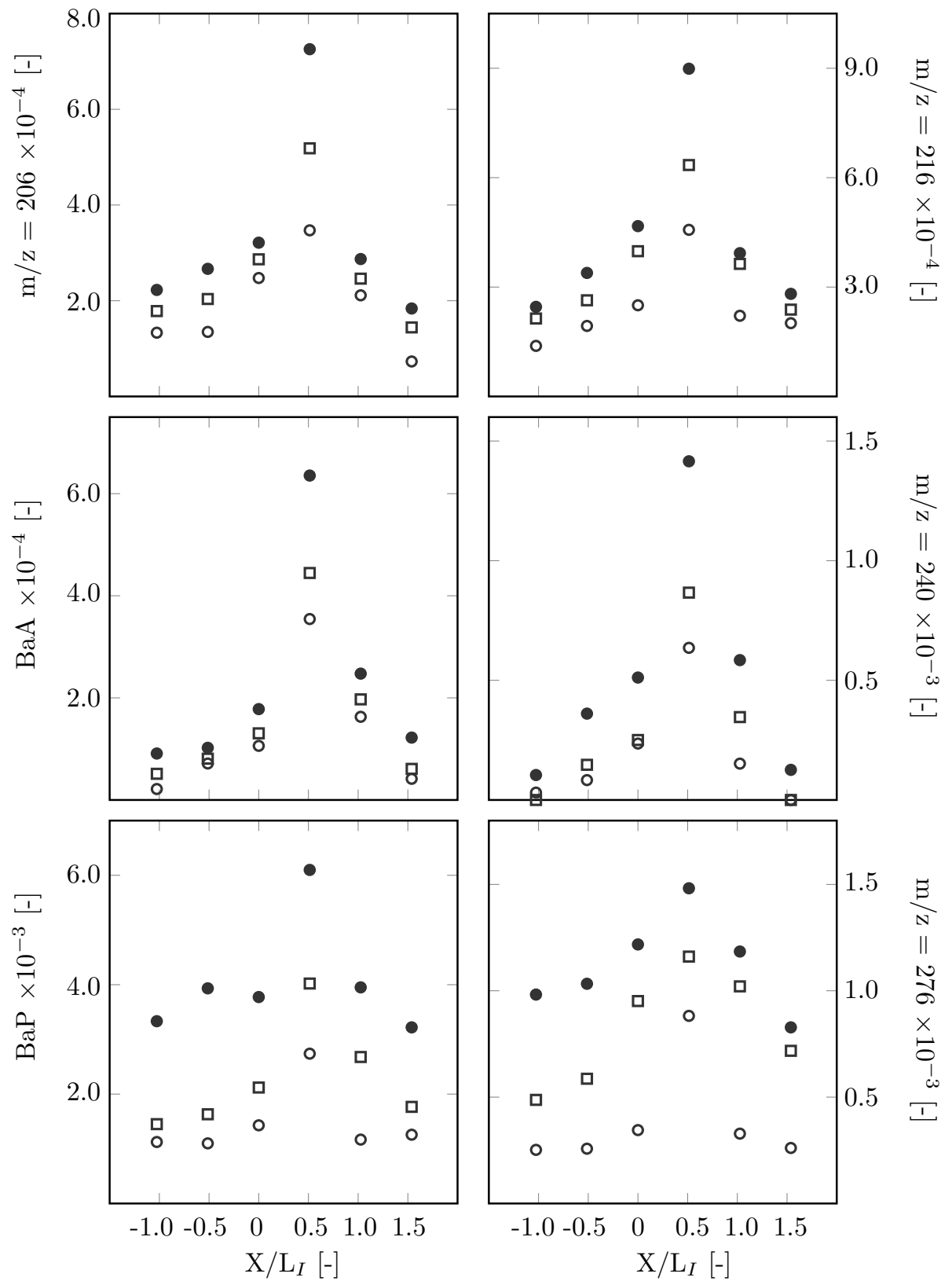

Figure 12 (Cont.): The impact of equivalence ratio on the extracted distribution of PAHs along reaction zone layer at a constant $a_{T}=420 \mathrm{~s}^{-1}$ and $T_{H C P}=1500 \mathrm{~K}$. The concentrations correspond to the mole fractions of PAH $(92 \leq \mathrm{m} / \mathrm{z}[\mathrm{u}] \leq 300)$ in the analysed liquid sample including the solvent $(\mathrm{DCM})$ contribution. Open circle $-\phi_{U N}=1.8$; Square $-\phi_{U N}=2.0 ;$ Filled circle $-\phi_{U N}=2.2 . \mathrm{X} / \mathrm{L}_{I}>0$ is towards reactants and $\mathrm{X} / \mathrm{L}_{I}<0$ towards the hot combustion products. 

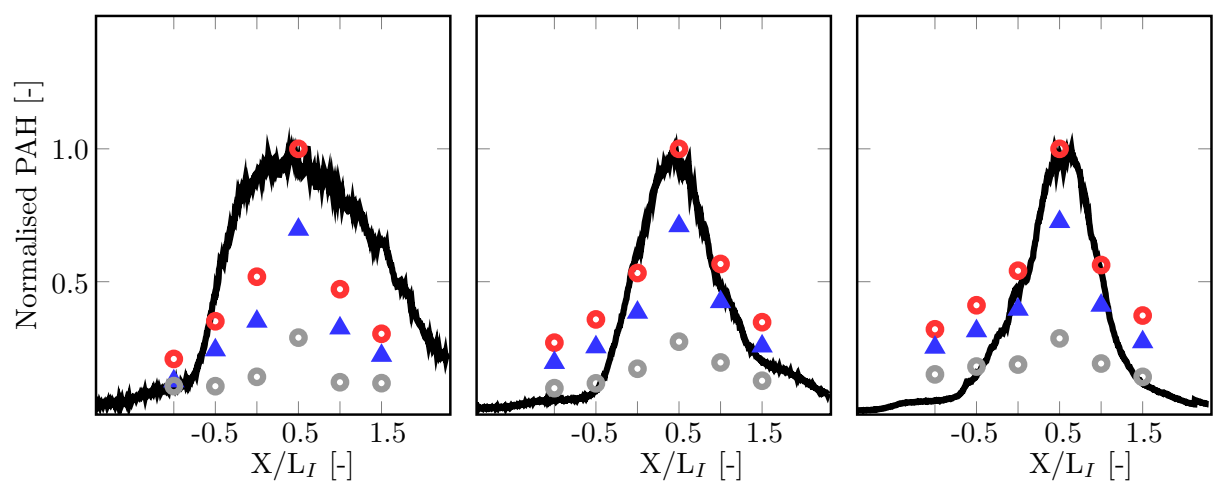

Figure 13: Normalised total PAH concentrations from probe measurements (circle) and PAH-PLIF signals (black line) along the centreline for different equivalence ratios of $\phi_{U N}=1.8$ (left), 2.0 (middle) and 2.2 (right). Each case is normalised by the corresponding peak. The burnt gas temperature $\mathrm{T}_{H C P}=1500 \mathrm{~K}$ and total rate of strain $\mathrm{a}_{T}=420 \mathrm{~s}^{-1}$. The relatively high laser fluence at $355 \mathrm{~nm}$ suggests that soot particle incandescence contributes to the PAH - LIF signal [57]. Thus, this data is likely to include contributions from PAHs infused on soot particles as well as gaseous species. The probe results correspond to the analysis of liquid samples, including the solvent (DCM) contribution, for three different conditions: Red circle - the fraction of PAHs in the range of $92 \leq \mathrm{m} / \mathrm{z}[\mathrm{u}] \leq 300$; Blue triangle - PAHs with three or more rings $(154 \leq \mathrm{m} / \mathrm{z}[\mathrm{u}] \leq$ 300); Grey circle - PAHs with five rings $(\mathrm{m} / \mathrm{z}=252$ and 276$)$.

strain has a significant impact on the formation of PAHs and soot. Furthermore, the peak ratio of total PAH species in the measured mass spectra increases by a factor of 3.05 when the total rate of strain is reduced from $a_{T}=420 \mathrm{~s}^{-1}$ to $a_{T}=225 \mathrm{~s}^{-1}$ and an increase from $a_{T}=420 \mathrm{~s}^{-1}$ to $a_{T}=610 \mathrm{~s}^{-1}$ results in a reduction in the peak ratio by a factor of 0.48 . The clear implication is that soot formation is a low Da number process due to long chemical time scales. The probe measurements are consistent with the non-intrusive laser diagnostics and show a peak in PAH concentrations close to $\mathrm{X} / L_{I}=0.5$ as a result of the balance between formation and oxidation. As shown in Fig. 13, there is a reasonable correspondence throughout the flame brush between the relative PAH concentrations obtained from $\mathrm{PAH}-$ 
PLIF and probe measurements. The PAH-LIF data is normalised by the corresponding maximum value for each case. The total PAH fractions obtained from the probe measurements are normalised by the full mass range covering $92 \leq \mathrm{m} / \mathrm{z}[\mathrm{u}] \leq 300$. The fraction of PAHs, shown in Fig. 13, is provided for (i) the full range $(92 \leq \mathrm{m} / \mathrm{z}[\mathrm{u}] \leq 300)$ (red), (ii) the fraction with three and more rings $(154 \leq \mathrm{m} / \mathrm{z}[\mathrm{u}] \leq 300)$ (blue) and (iii) the fraction of five ring PAHs $(\mathrm{m} / \mathrm{z}=252$ and 276) (grey). It should be emphasised that the current PAH-LIF signal stems (predominantly) from PAHs with three or more rings and thus omits prevalent smaller aromatics such as naphthalene. As shown in Fig. 13, the analysis indicates that the probe measurements and PAH-LIF data show peaks in the PAH concentrations at $\mathrm{X} / \mathrm{L}_{I}=0.5$. The differences between the PAH-LIF data and probe measurements may partly arise from a more efficient extraction of heavier PAHs from the probe sample and the omission of smaller aromatics from the PAH-LIF data. However, it should be emphasised that a complete comparison is impossible as the GC/MS (probe measurements) provides species concentrations up to $\mathrm{m} / \mathrm{z}=$ 300, while PAHs identified using PAH-PLIF contain a mixture of distinct functional groups with broad spectra. The used excitation wavelength and laser fluence at $355 \mathrm{~nm}$ are likely to cause some level of crosstalk between PAH-LIF and ELS detection system. Thus, the applied laser induced fluorescence method cannot distinguish PAHs present in the gas phase or infused on soot particles.

Mean concentration profiles of major PAHs (e.g. $1-\mathrm{MN}, \mathrm{m} / \mathrm{z}=154, \mathrm{~m} / \mathrm{z}$ $=276$ and $\mathrm{B}(\mathrm{a}) \mathrm{P})$ indicate potential contributions to the formation of particulates with $\mathrm{B}(\mathrm{a}) \mathrm{P}$ present in relatively large quantities irrespective of lightly 
or heavily sooting conditions. It is important to note that PAH concentrations are comparatively low before applying the centrifuge process as shown in Fig. 6(b). This illustrates the importance of PAH adsorption on soot particles. The concentrations of acenaphthylene and acenaphthene are consistently low from lightly to heavily sooting conditions indicating a difference balance between formation and consumption. For example, the reaction flux through these species leading to soot particles may be significant. Benzo(b)fluoranthene also reaches to a maximum at $\mathrm{X} / L_{I}=0.5$, yet decreases significantly faster towards both boundaries of the reaction layer. The detected concentration of pyrene is much lower than that of benzo(a)pyrene and the amount determines the collision probability (e.g. with a soot particle). However, while pyrene and benzo(a)pyrene appear closely related from a chemical point of view, structural differences may result in differences in the reaction flux leading to soot particle growth via PAH adsorption due to different sticking probabilities.

The coupling between gas-phase and surface reactions [97] is an important factor and, as shown above, PAH adsorption onto soot particles assumes a distinct role. Soot nucleation is proportional to PAH concentrations [98] with higher concentrations leading to a higher collision frequency. However, the probability of stabilisation depends on a number of other factors such as PAH size and orientation. Figures 15 and 16 show the evolution of the relative concentrations of the main PAHs in the size range $92 \leq m / z \leq 300 \mathrm{amu}$ over the entire reaction zone. The mole fractions of species in the analysed liquid sample include the solvent (DCM) contribution and the PAHs infused on soot particles that can be separated as outlined above. 
The data indicates the evolution of the balance between formation and consumption over the reaction zone layer. The appearance of high concentrations of PAHs at $\mathrm{X} / L_{I}=0.5$ indicates the location of soot nucleation. The stoichiometry of the reactant mixture $\left(\phi_{U N}\right)$ and the total rate of strain $\left(a_{T}\right)$ have a remarkable impact on evolution of PAH concentrations in the reaction zone layer. While B(a)P shows persistently high concentrations over the entire reaction zone irrespective of the conditions, the evolution of other species are strongly dependent on both the spatial location and sooting conditions. For example, the relative concentration of $\mathrm{m} / \mathrm{z}=154$ (second highest peak) overtakes $\mathrm{m} / \mathrm{z}=276$ at $\mathrm{X} / L_{I}=+0.5$ and +1.0 at $\phi_{U N}=2.2$ although the concentrations are close at the boundaries of $\mathrm{X} / \mathrm{L}_{I}=-1.0$ and +1.5 . The concentrations of $\mathrm{m} / \mathrm{z}=228$ and $\mathrm{m} / \mathrm{z}=240$ appear to be higher than $\mathrm{m} / \mathrm{z}$ $=276$ in the region of soot inception at $\mathrm{X} / L_{I}=+0.5$. This indicates a different balance of formation and loss mechanisms for these PAHs. At a lower rate of strain, $\mathrm{B}(\mathrm{a}) \mathrm{P}$ still shows the highest concentration with $\mathrm{m} / \mathrm{z}=154$ the secondary species. However, the concentration of $\mathrm{m} / \mathrm{z}=142$ (methylnaphthalene isomers) is particularly high with competition between $\mathrm{m} / \mathrm{z}=$ $132, \mathrm{~m} / \mathrm{z}=142$ and $\mathrm{m} / \mathrm{z}=146$ as the third highest species. The impact of $\mathrm{m} / \mathrm{z}=276$ is less pronounced in contrast to $\phi_{U N}=2.2$. It is expected that such detailed information on the relative abundance of different PAHs associated with soot nucleation will provide a validation target for comprehensive models describing soot inception in turbulent flows. 

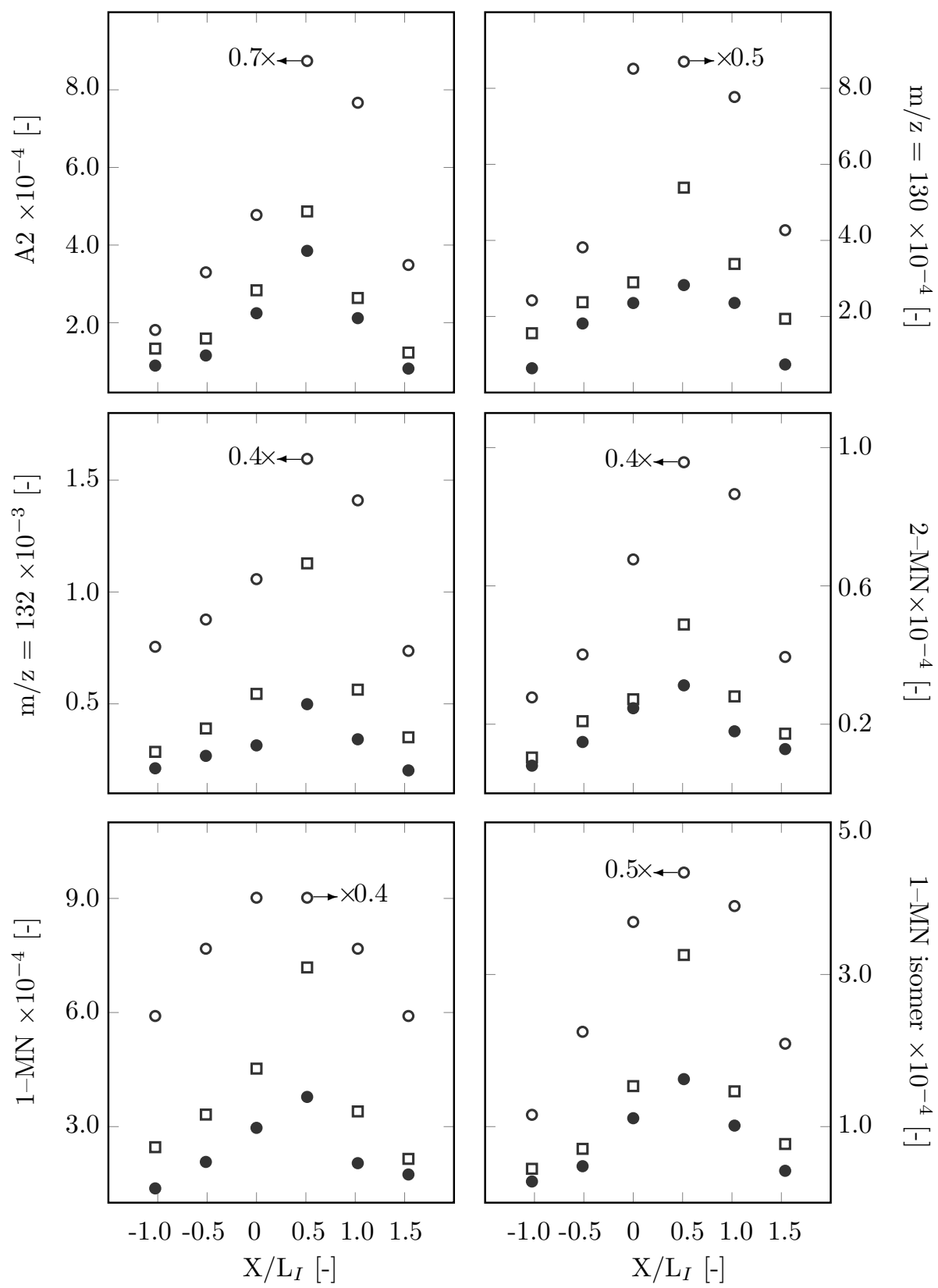

Figure 14: The impact of the rate of strain on the extracted distribution of PAHs along reaction zone layer for $\phi_{U N}=2.0$ and $T_{H C P}=1500 \mathrm{~K}$. The concentrations correspond to the mole fractions of PAH $(92 \leq \mathrm{m} / \mathrm{z}[\mathrm{u}] \leq 300)$ in the analysed liquid sample including the solvent (DCM) contribution. Open circle $-a_{T}=225 \mathrm{~s}^{-1}$; Square $-a_{T}=420 \mathrm{~s}^{-1}$; Filled circle $-a_{T}=610 \mathrm{~s}^{-1}$. $\mathrm{X} / \mathrm{L}_{I}>0$ is towards reactants and $\mathrm{X} / \mathrm{L}_{I}<0$ towards the hot combustion products. 

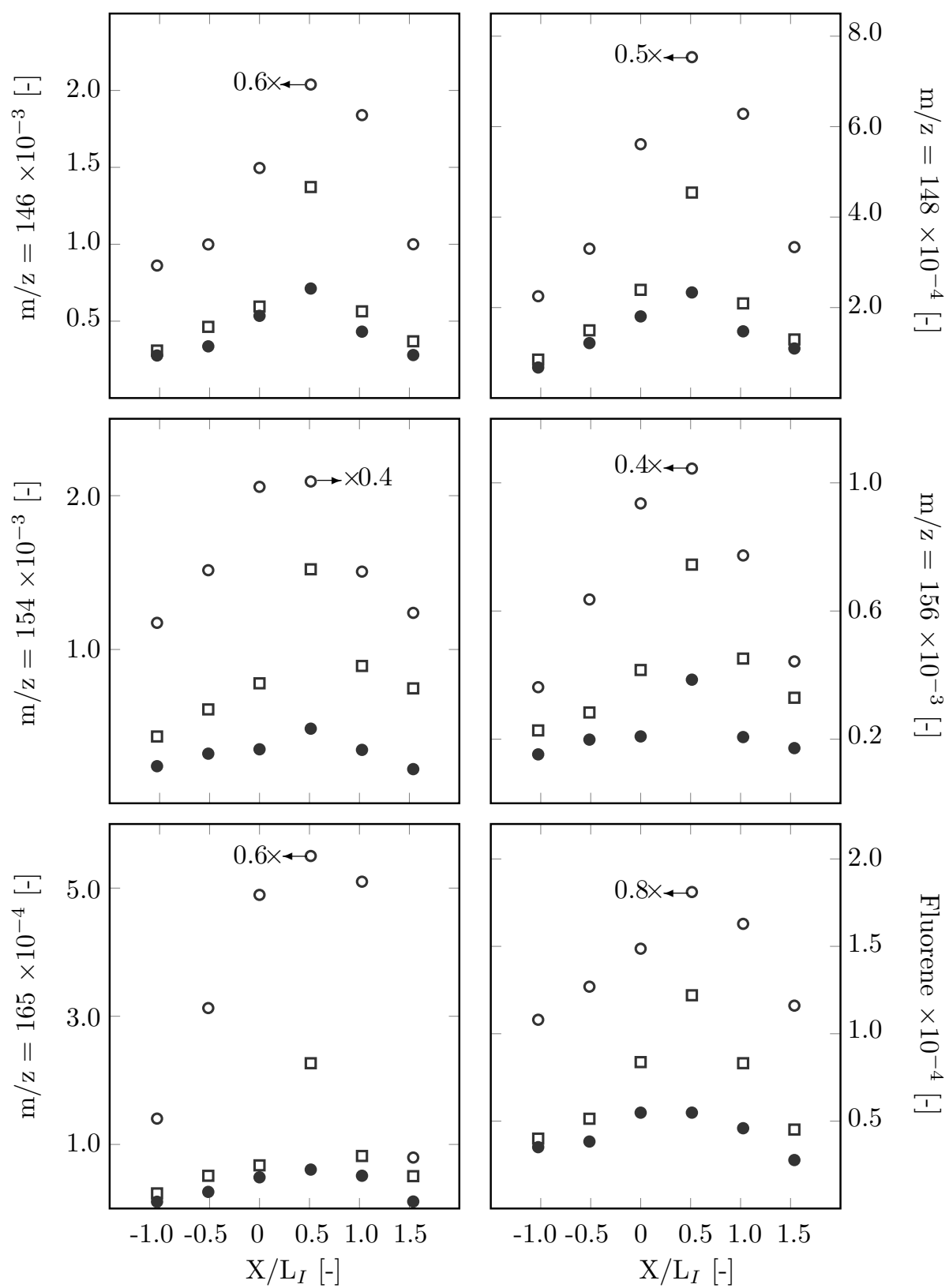

Figure 14 (Cont.): The impact of the rate of strain on the extracted distribution of PAHs along reaction zone layer for $\phi_{U N}=2.0$ and $T_{H C P}=1500 \mathrm{~K}$. The concentrations correspond to the mole fractions of PAH $(92 \leq \mathrm{m} / \mathrm{z}[\mathrm{u}] \leq 300)$ in the analysed liquid sample including the solvent (DCM) contribution. Open circle $-a_{T}=225 \mathrm{~s}^{-1}$; Square $a_{T}=420 s^{-1} ;$ Filled circle $-a_{T}=610 s^{-1} . \mathrm{X} / \mathrm{L}_{I}>0$ is towards reactants and $\mathrm{X} / \mathrm{L}_{I}<0$ towards the hot combustion products. 

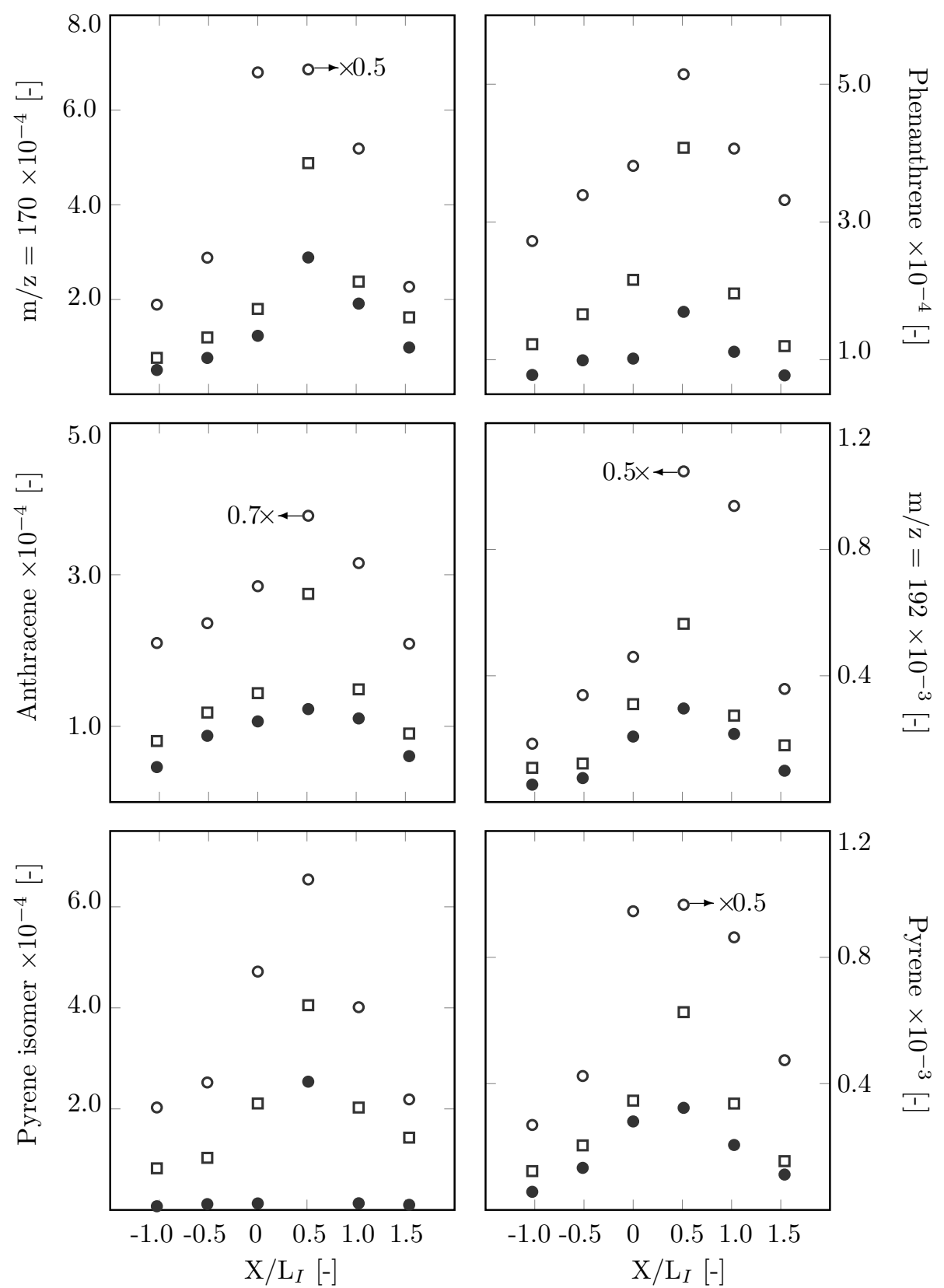

Figure 14 (Cont.): The impact of the rate of strain on the extracted distribution of PAHs along reaction zone layer for $\phi_{U N}=2.0$ and $T_{H C P}=1500 \mathrm{~K}$. The concentrations correspond to the mole fractions of PAH $(92 \leq \mathrm{m} / \mathrm{z}[\mathrm{u}] \leq 300)$ in the analysed liquid sample including the solvent (DCM) contribution. Open circle $-a_{T}=225 \mathrm{~s}^{-1}$; Square $a_{T}=420 s^{-1}$; Filled circle $-a_{T}=610 s^{-1} . \mathrm{X} / \mathrm{L}_{I}>0$ is towards reactants and $\mathrm{X} / \mathrm{L}_{I}<0$ towards the hot combustion products. 

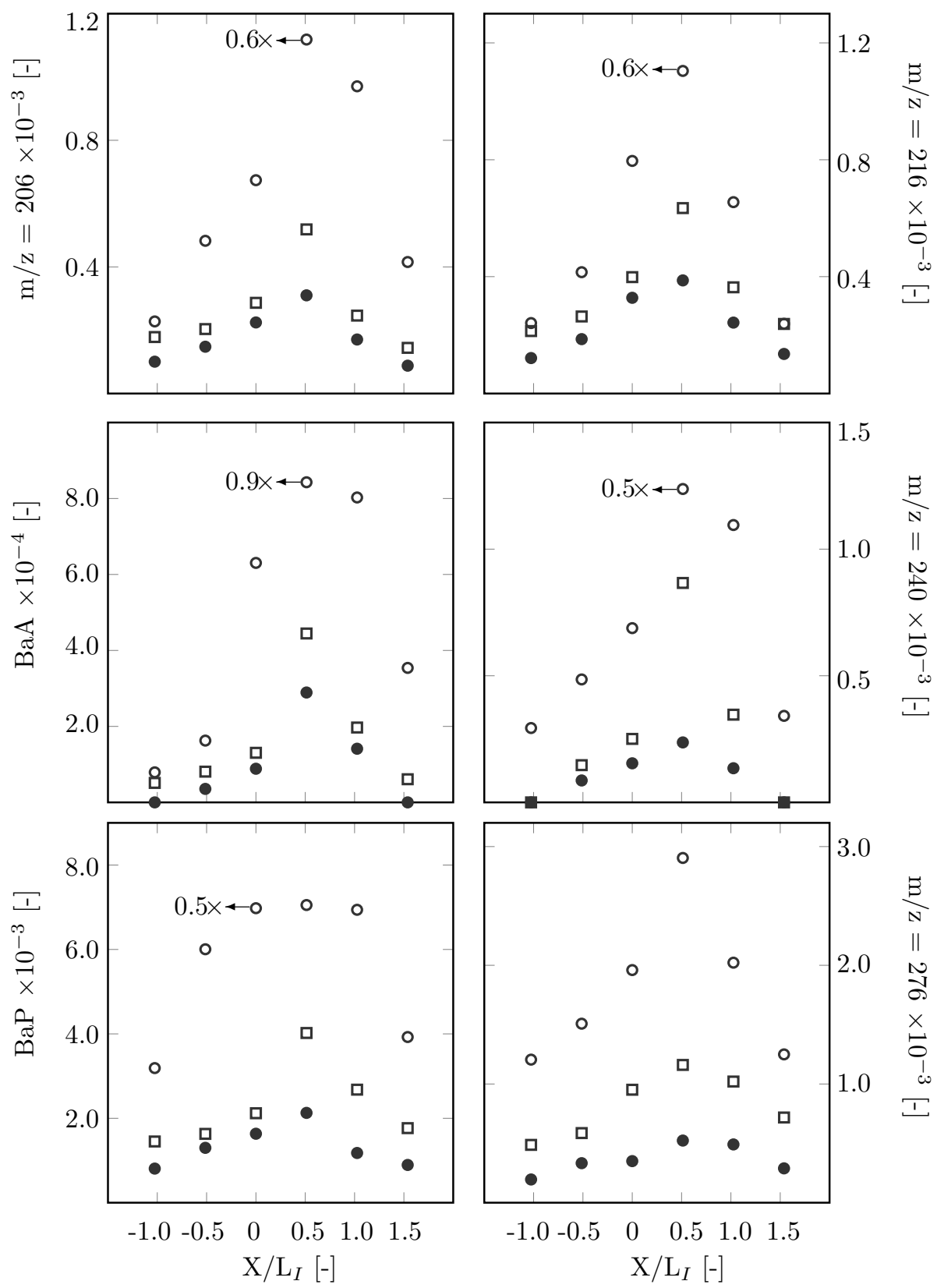

Figure 14 (Cont.): The impact of the rate of strain on the extracted distribution of PAHs along reaction zone layer for $\phi_{U N}=2.0$ and $T_{H C P}=1500 \mathrm{~K}$. The concentrations correspond to the mole fractions of PAH $(92 \leq \mathrm{m} / \mathrm{z}[\mathrm{u}] \leq 300)$ in the analysed liquid sample including the solvent (DCM) contribution. Open circle $-a_{T}=225 \mathrm{~s}^{-1}$; Square $a_{T}=420 s^{-1}$; Filled circle $-a_{T}=610 s^{-1} . \mathrm{X} / \mathrm{L}_{I}>0$ is towards reactants and $\mathrm{X} / \mathrm{L}_{I}<0$ towards the hot combustion products. 

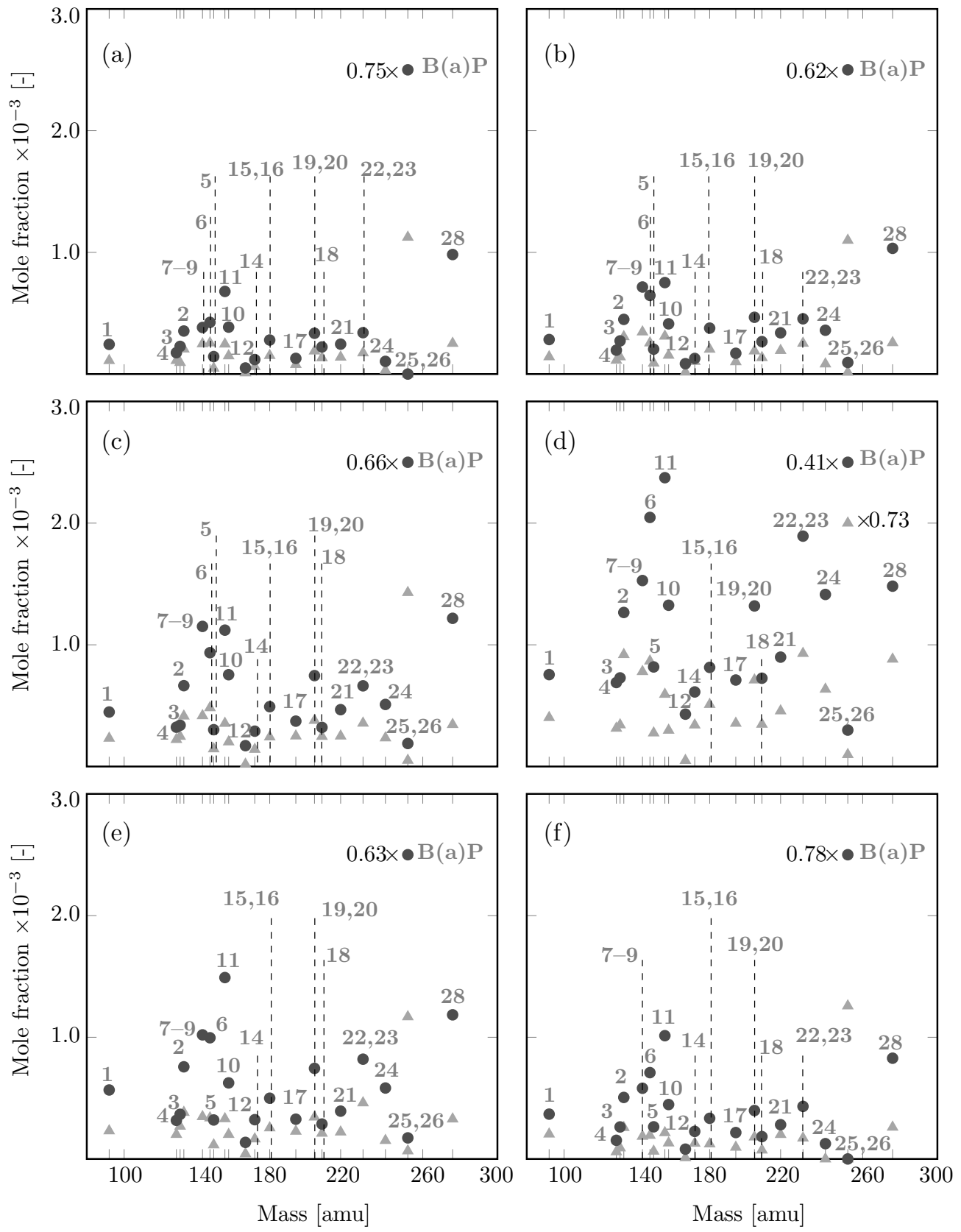

Figure 15: The impact of equivalence ratio on the PAH mass distribution at different spatial locations at $a_{T}=420 \mathrm{~s}^{-1}$ and $T_{H C P}=1500 \mathrm{~K}$. The label corresponds to species listed in Table 3. The concentrations correspond to the mole fractions of PAH $(92 \leq \mathrm{m} / \mathrm{z}$ $[\mathrm{u}] \leq 300)$ in the analysed liquid sample including the solvent $(\mathrm{DCM})$ contribution. (a) $\mathrm{X} / L_{I}=-1$; (b) $\mathrm{X} / L_{I}=-0.5$; (c) $\mathrm{X} / L_{I}=0$; (d) $\mathrm{X} / L_{I}=+0.5$; (e) $\mathrm{X} / L_{I}=+1$; (f) $\mathrm{X} / L_{I}=+1.5$. Triangle $-\phi_{U N}=1.8 ;$ Circle $-\phi_{U N}=2.2$. 

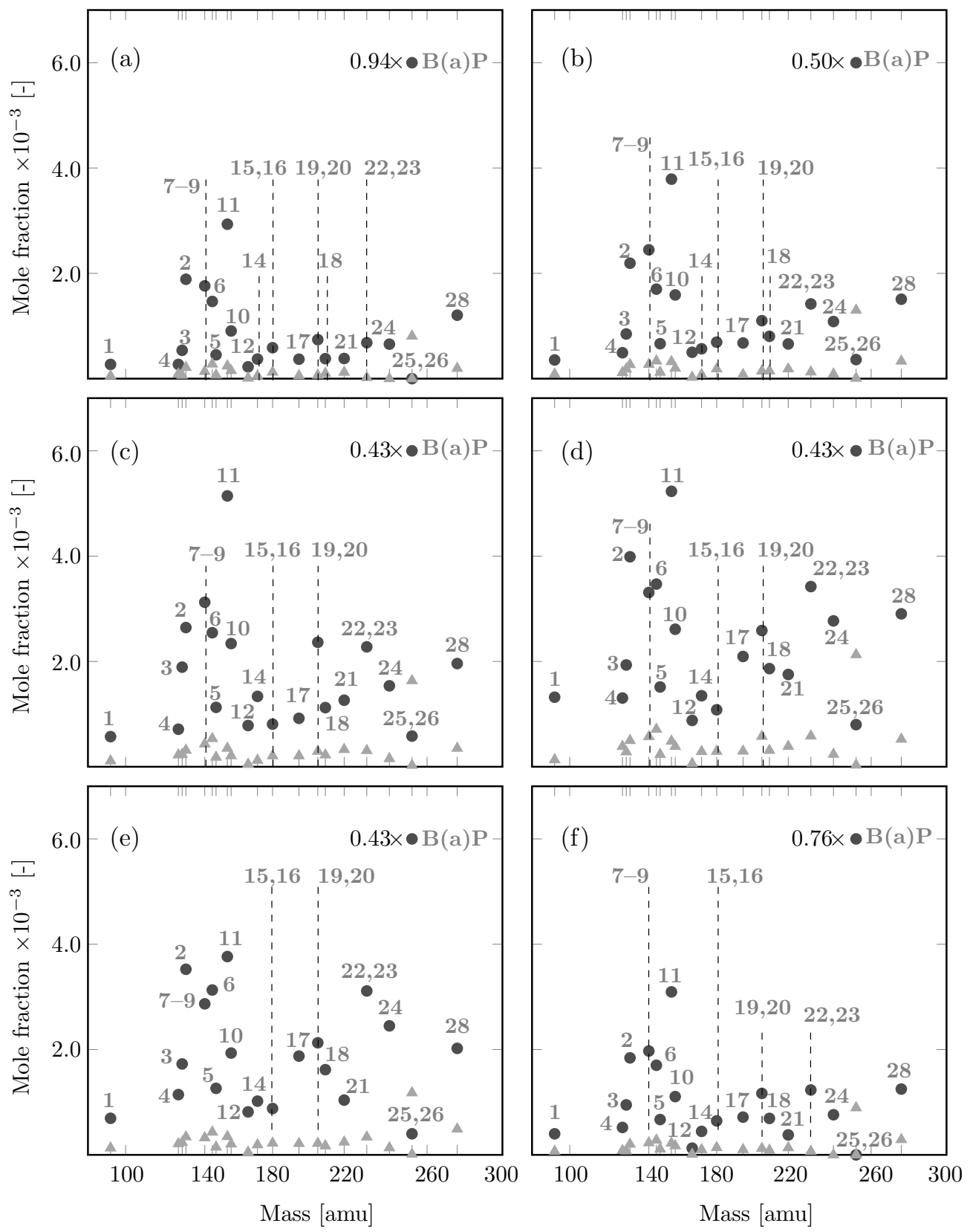

Figure 16: The impact of the rate of strain rate on the PAH mass distribution at different spatial locations for $\phi_{U N}=2.0$ and $T_{H C P}=1500 \mathrm{~K}$. The label corresponds to species listed in Table 3. The concentrations correspond to the mole fractions of PAH $(92 \leq \mathrm{m} / \mathrm{z}$ $[\mathrm{u}] \leq 300)$ in the analysed liquid sample including the solvent $(\mathrm{DCM})$ contribution. (a) $\mathrm{X} / L_{I}=-1$; (b) $\mathrm{X} / L_{I}=-0.5$; (c) $\mathrm{X} / L_{I}=0$; (d) $\mathrm{X} / L_{I}=+0.5 ;$ (e) $\mathrm{X} / L_{I}=+1$; (f) $\mathrm{X} / L_{I}=+1.5$. Triangle $-a_{T}=610 \mathrm{~s}^{-1} ;$ Circle $-a_{T}=255 \mathrm{~s}^{-1}$. 


\section{Conclusions}

A back-to-burnt opposed jet configuration has been used to study the overall flame structure of turbulent premixed ethylene/air flames and the relative concentrations of PAHs associated with soot inception. The experiments covered a series of sooting flame conditions with variations in the equivalence ratio and the rate of strain. The conditions traverse the soot inception limit with non-intrusive ELS and PAH-PLIF combined probe sampling to quantify gaseous and PAH species using GC-TCD and GC-MS, respectively. It is shown that the rate of strain exerts a substantial influence on both PAH concentrations and soot formation. Hence, it is likely that soot formation in turbulent flames becomes dominated by contributions from low strain regions. It has also been shown that the stoichiometry of the mixture controls the concentrations of PAHs associated with soot inception. The latter aspect has been further analysed by determining the PAH mass spectra over the reaction zone layer. It is shown that PAH layers extend to three integral length scales of turbulence. A variation of the temperature of the opposing stream of hot combustion products, used to stabilise the flames, indicates that a value of around $1500 \mathrm{~K}$ prior to mixing with the reactants provides optimal conditions for PAH and soot growth.

The results obtained clearly show that benzo(a)pyrene is prevalent in the flame structure and that relatively large amounts are condensed onto soot particles. In addition to $\mathrm{B}(\mathrm{a}) \mathrm{P}$ and $\mathrm{m} / \mathrm{z}=252 \mathrm{u}$, the prevalence of species with $\mathrm{m} / \mathrm{z}=142,154$ and 276 indicate a potentially significant role in particle formation due to their high concentration levels. The current determination of the relative distribution of PAHs across the flame structure, 
the impact on soot inception of reactant composition and the rate of strain will likely advance the fundamental understanding of the particle formation and oxidation process in turbulent premixed sooting flames. It is hence expected that the results will support the development of computational models that account better for the influence of PAHs on soot inception and growth in turbulent flames.

\section{Acknowledgments}

Hamed Shariatmadar would like to acknowledge the financial support offered by the Imperial College London Ph.D. President Scholarship Scheme.

\section{References}

[1] J. L. Durant, W. F. Busby, A. L. Lafleur, B. W. Penman, C. L. Crespi, Human cell mutagenicity of oxygenated, nitrated and unsubstituted polycyclic aromatic hydrocarbons associated with urban aerosols, $\mathrm{Mu}-$ tat. Res. Genet. Toxicol. 371 (1996) 123-157.

[2] C. S. McEnally, L. D. Pfefferle, B. Atakan, K. Kohse-Höinghaus, Studies of aromatic hydrocarbon formation mechanisms in flames: Progress towards closing the fuel gap, Prog. Energy Combust. Sci. 32 (2006) 247294.

[3] H. Shariatmadar, F. Hampp, R. P. Lindstedt, Quantification of PAH concentrations in premixed turbulent flames crossing the soot inception limit, Proc. Comb. Inst. 38 (2021) 1163-1172. 
[4] C. E. Boström, P. Gerde, A. Hanberg, B. Jernström, C. Johansson, T. Kyrklund, A. Rannug, M. Törnqvist, K. Victorin, R. Westerholm, Cancer risk assessment, indicators, and guidelines for polycyclic aromatic hydrocarbons in the ambient air, Environ. Health Perspect. 110 (2002) $451-488$.

[5] K. Straif, R. Baan, Y. Grosse, B. Secretan, F. E. Ghissassi, V. Cogliano, Carcinogenicity of polycyclic aromatic hydrocarbons, Lancet Oncol. 6 (2005) 931-932.

[6] M. Arienzo, M. Toscanesi, M. Trifuoggi, L. Ferrara, C. Stanislao, C. Donadio, V. Grazia, D. V. Gionata, F. Carella, Contaminants bioaccumulation and pathological assessment in Mytilusgalloprovincialis in coastal waters facing the brownfield site of Bagnoli, Italy, Mar. Pollut. Bull. 140 (2019) 341-352.

[7] M. D. Avakian, B. Dellinger, H. Fiedler, B. Gullet, C. Koshland, S. Marklund, The origin, fate, and health effects of combustion byproducts: a research framework, Environ. Health Perspect. 110 (2002) $1155-1162$.

[8] Regulatory impact analyses for the particulate matter and ozone national ambient air quality standards and proposed regional haze rule. Washington, DC: U.S. Environmental Protection Agency; 1997, http://www.epa.gov/ttn/oartg/naaqsfin/ria.html.

[9] S. Masala, T. Ahmed, C. Bergvall, R. Westerholm, Improved efficiency of extraction of polycyclic aromatic hydrocarbons (PAHs) from the na- 
tional institute of standards and technology (NIST) standard reference material diesel particulate matter (SRM 2975) using accelerated solvent extraction, Anal. Bioanal. Chem. 401 (2011) 3305-3315.

[10] M. Shrivastava, S. Lou, A. Zelenyuk, R. C. Easter, R. A. Corley, B. D. Thrall, P. J. Rasch, J. D. Fast, S. L. Massey Simonich, H. Shen, S. Tao, Global long-range transport and lung cancer risk from polycyclic aromatic hydrocarbons shielded by coatings of organic aerosol, Proc. Natl. Acad. Sci. 114 (2017) 1246-1251.

[11] G. Blanquart, H. Pitsch, Analyzing the effects of temperature on soot formation with a joint volume-surface-hydrogen model, Combust. Flame 156 (2009) 1614-1626.

[12] X. Mercier, O. Carrivain, C. Irimiea, A. Faccinetto, E. Therssen, Dimers of polycyclic aromatic hydrocarbons: the missing pieces in the soot formation process, Phys. Chem. Chem. Phys. 21 (2019) 8282-8294.

[13] K. O. Johansson, T. Dillstrom, P. Elvati, M. F. Campbell, P. E. Schrader, D. M. Popolan-Vaida, N. K. Richards-Henderson, K. R. Wilson, A. Violi, H. A. Michelsen, Radical-radical reactions, pyrene nucleation, and incipient soot formation in combustion, Proc. Combust. Inst. 36 (2017) 799-806.

[14] K. O. Johansson, M. P. Head-Gordon, P. E. Schrader, K. R. Wilson, H. A. Michelsen, Resonance-stabilized hydrocarbon-radical chain reactions may explain soot inception and growth, Sci. 361 (2018) 97-100. 
[15] P. Liu, Z. Li, A. Bennett, H. Lin, S. M. Sarathy, W. L. Roberts, The site effect on PAHs formation in HACA-based mass growth process, Combust. Flame 199 (2019) 54-68.

[16] F. Schulz, M. Commodo, K. Kaiser, G. De Falco, P. Minutolo, G. Meyer, A. D'Anna, L. Gross, Insights into incipient soot formation by atomic force microscopy, Proc. Combust. Inst. 37 (2019) 885-892.

[17] M. Commodo, K. Kaiser, G. D. Falco, P. Minutolo F. Schulz, A. D'Anna, L. Gross, On the early stages of soot formation: Molecular structure elucidation by high-resolution atomic force microscopy, Combust. Flame 205 (2019) 154-164.

[18] P. Liu, Z. Li, W. L. Roberts, The growth of PAHs and soot in the post-flame region, Proc. Combust. Inst. 37 (2019) 977-984.

[19] A. G. G. M. Tielens, Interstellar polycyclic aromatic hydrocarbon molecules, Annu. Rev. Astron. Astrophys. 46 (2008) 289-337.

[20] Q. Mao, D. Hou, K. H. Luo, X. You, Dimerization of polycyclic aromatic hydrocarbon molecules and radicals under flame conditions, J. Phys. Chem. A 122 (2018) 8701-8708.

[21] A. Faccinetto, C. Irimiea, P. Minutolo, M. Commodo, A. D'Anna, N. Nuns, Y. Carpentier, C. Pirim, P. Desgroux, C. Focsa, X. Mercier, Evidence on the formation of dimers of polycyclic aromatic hydrocarbons in a laminar diffusion flame, Commun. Chem. 112 (2020) 1-8.

[22] B. D. Adamson, S.A. Skeen, M. Ahmed, N. Hansen, Detection of aliphatically bridged multi-core polycyclic aromatic hydrocarbons in sooting 
flames with atmospheric-sampling high-resolution tandem mass spectrometry, J Phys Chem A 122 (2018) 9338-9349.

[23] H. Sabbah, L. Biennier, S. J. Klippenstein, I. R. Sims, B. R. Rowe, Exploring the Role of PAHs in the Formation of Soot: Pyrene Dimerization, J. Phys. Chem. Lett. 19 (2010) 2962-2967.

[24] H. Wang, Formation of nascent soot and other condensed-phase materials in flames, Proc. Comb. Inst. 33 (2011) 41-67.

[25] S. Chung, A. Violi, Peri-condensed aromatics with aliphatic chains as key intermediates for the nucleation of aromatic hydrocarbons, Proc. Comb. Inst. 33 (2011) 693-700.

[26] J. S. Lowe, J. Y. W. Lai, P. Elvati, A. Violi, Towards a predictive model for polycyclic aromatic hydrocarbon dimerization propensity, Proc. Comb. Inst. 35 (2015) 1827-1832.

[27] T. S. Totton, A. J. Misquitta, M. Kraft, A quantitative study of the clustering of polycyclic aromatic hydrocarbons at high temperatures, Phys. Chem. Chem. Phys. 14 (2012) 4081-4094.

[28] H. Zhang, X. You, H. Wang, C. K. Law, Dimerization of polycyclic aromatic hydrocarbons in soot nucleation, J. Phys. Chem. 118 (2014) $1287-1292$.

[29] H. A. Michelsen, M. B. Colket, P.-E. Bengtsson, A. D'Anna, P. Desgroux, B. S. Haynes, J. H. Miller, G. J. Nathan, H. Pitsch, H. Wang, A Review of Terminology Used to Describe Soot Formation and Evolution 
under Combustion and Pyrolytic Conditions, ACS Nano 14(10) (2020) 12470-12490.

[30] F. Bisetti, G. Blanquart, M. E. Mueller, and H. Pitsch, On the formation and early evolution of soot in turbulent nonpremixed flames, Combust. Flame 159 (2012) 317-335.

[31] D. F. Kronholm, J. B. Howard, Analysis of soot surface growth pathways using published PFR data with new PSD measurements and published premixed flame data, Proc. Combust. Inst 28 (2000) 2555-2561.

[32] K. O. Johansson, F. E. Gabaly, P. E. Schrader, M. F. Campbell, H. A. Michelsen, Evolution of maturity levels of the particle surface and bulk during soot growth and oxidation in a flame, Aerosol. Sci. Tech. 51 (2017) 1333-1344.

[33] S. B. Dworkin, Q. Zhang, M. J. Thomson, N. A.Slavinskaya, U. Riedel, Application of an enhanced PAH growth model to soot formation in a laminar coflow ethylene/air diffusion flame, Combust. Flame 158 (2011) 1682-1695.

[34] R. P. Lindstedt, B. B. O. Waldheim, Modeling of soot particle size distributions in premixed stagnation flow flames, Proc. Combust. Inst. 34 (2013) 1861-1868.

[35] M. A. Schiener, R. P. Lindstedt, Transported probability density function based modelling of soot particle size distributions in non-premixed turbulent jet flames, Proc. Combust. Inst. 37 (2019) 1049-1056. 
[36] W. R. Boyette, S. Chowdhury, W. L. Roberts, Soot particle size distribution functions in a turbulent non-premixed ethylene-nitrogen flame, Flow Turbul. Combust. 98 (2017) 1173-1186.

[37] S. M. Mahmoud, G. J. Nathan, Z. T. Alwahabi, Z. W. Sun, P. R. Medwell, and B. B. Dally, The effect of exit strain rate on soot volume fraction in turbulent non-premixed jet flames, Proc. Combust. Inst. 36 (2017) 889-897.

[38] S. M. Mahmoud, G. J. Nathan, Z. T. Alwahabi, Z. W. Sun, P. R. Medwell, B. B. Dally, The effect of exit Reynolds number on soot volume fraction in turbulent non-premixed jet flames, Combust. Flame 187 (2018) 42-51.

[39] K. P. Geigle, M. Köhler, W. O'Loughlin, and W. Meier, Investigation of soot formation in pressurized swirl flames by laser measurements of temperature, flame structures and soot concentrations, Proc. Combust. Inst. 35 (2015) 3373-3380.

[40] K. P. Geigle, W. O'Loughlin, R. Hadef, and W. Meier, Visualization of soot inception in turbulent pressurized flames by simultaneous measurement of laser induced fluorescence of polycyclic aromatic hydrocarbons and laser-induced incandescence, and correlation to $\mathrm{OH}$ distributions, Appl. Phys. B 119 (2015) 717-730.

[41] M. E. Mueller, H. Pitsch, LES model for sooting turbulent nonpremixed flames, Combust. Flame 159 (2012) 2166-2180. 
[42] C. S. Yoo, H. G. Im, Transient soot dynamics in turbulent nonpremixed ethylene-air counterflow flames. Proc. Combust. Inst. 31 (2007) 701708.

[43] L. Tian, M. A. Schiener and R. P. Lindstedt, Fully coupled sectional modelling of soot particle dynamics in a turbulent diffusion flame, Proc. Combustion Inst. 38 (2020), available online http://dx.doi.org/10.1016/j.proci.2020.06.093

[44] K. H. H. Goh, P. Geipel, R. P. Lindstedt, Turbulent transport in premixed flames approaching extinction, Proc. Combust. Inst. 35 (2015) $1469-1476$.

[45] P. Geipel, K. H. H. Goh, R. P. Lindstedt, Fractal-generated turbulence in opposed jet flows, Flow Turbul. Combust. 85 (2010) 397-419.

[46] F. Hampp, R. P. Lindstedt, Quantification of combustion regime transitions in premixed turbulent DME flames, Combust. Flame 182 (2017) $248-268$.

[47] K. H. H. Goh, P. Geipel, R. P. Lindstedt, Lean premixed opposed jet flames in fractal grid generated multiscale turbulence, Combust. Flame 161 (2014) 2419-2434.

[48] K. H. H. Goh, P. Geipel, F. Hampp, R. P. Lindstedt, Flames in fractal grid generated turbulence, Fluid Dyn. Res. 45 (6) (2013) 061403.

[49] F. Hampp, R. P. Lindstedt, Strain distribution on material surfaces during combustion regime transitions, Proc. Combust. Inst. 36 (2017) $1911-1918$. 
[50] L. W. Kostiuk, K. N. C. Bray, T. C. Chew, Premixed turbulent combustion in counterflowing streams, Combust. Sci. Technol. 64 (1989) 233-241.

[51] W. K. George, H. J. Hussein, Locally axisymmetric turbulence, J. Fluid Mech. 233 (1991) 1-23.

[52] F. Hampp, R. P. Lindstedt, Quantification of fuel chemistry effects on burning modes in turbulent premixed flames, Combust. Flame 218 (2020) 134-149.

[53] F. Hampp, S. Shariatmadar, R. P. Lindstedt, Quantification of low Damköhler number turbulent premixed flames, Proc. Combust. Inst. 37 (2019) 1047-1054.

[54] S. Bejaoui, X. Mercier, P. Desgroux, E. Therssen, Laser induced fluorescence spectroscopy of aromatic species produced in atmospheric sooting flames using UV and visible excitation wavelengths, Combust. Flame 161 (2014) 2479-2491.

[55] K. Yamamoto, M. Takemoto, Measurement of PAH and soot of diffusion flames in a triple port burner, Fuel Proc. Technol. 107 (2013), 99-106.

[56] A. Ciajolo, R. Ragucci, B. Apicella, R. Barbella, M. de Joannon, A. Tregrossi, Fluorescence spectroscopy of aromatic species produced in rich premixed ethylene flames, Chemosphere 42 (2001) 835-841.

[57] T. Aizawa, H. Kosaka, Y. Matsui, 2-D Imaging of Soot Formation Process in a Transient Spray Flame by Laser-induced Fluorescence and Incandescence Techniques, SAE Technical Paper (2002), 2002-01-2669. 
[58] J. Simonsson, N.-E. Olofsson, S. Török, P.-E. Bengtsson, H. Bladh, Wavelength dependence of extinction in sooting flat premixed flames in the visible and near-infrared regimes, Appl. Phys. B 119 (2015) 657-667.

[59] R. M. Fristrom, and A. A. Westenberg, Flame Structures, McGraw-Hill, New York, 1965.

[60] U. Struckmeier, P. Oßwald, T. Kasper, L. Böhling, M. Heusing, M. Köhler, A. Brockhinke, K. Kohse-Höinghaus, Sampling probe influences on temperature and species concentrations in molecular beam mass spectroscopic investigations of flat premixed low-pressure flames, Z. Phys. Chem. 223 (2009) 503-537.

[61] F. N. Egolfopoulos, N. Hansen, Y. Ju, K. Kohse-Höinghaus, C. K. Law, F. Qi, Advances and challenges in laminar flame experiments and implications for combustion chemistry, Prog. Energy Combust. Sci. 43 (2014) $36-67$.

[62] J. Camacho, C. Liu, C. Gu, H. Lin, Z. Huang, Q. Tang, X. You, C. Saggese, Y. Li, H. Jung, L. Deng, I. Wlokas, H. Wang, Mobility size and mass of nascent soot particles in a benchmark premixed ethylene flame, Combust. Flame 162 (2015) 3810-3822.

[63] P. Zhang, Y. Kang, Z. Wu, X. Lu, Q. Wang, L. Mei, Effect of dimethyl ether addition on soot formation dynamics of ethylene Opposed-flow diffusion flames, Ind. Eng. Chem. Res. 58 (2019) 8370-8386.

[64] B. E. Anderson, A. J. Beyersdorf, C. H. Hudgins, J. V. Plant, K. L. Thornhill, E. L. Winstead, L. D. Ziemba, R. Howard, E. Corporan, 
R. C. Miake-Lye, S. C. Herndon, M. Timko, E. Wood, W. Dodds, P. Whitefield, D. Hagen, P. Lobo, W. B. Knighton, D. Bulzan, K. Tacina, C. Wey, R. Vander Wal, A. Bhargava, J. Kinsey, D. S. Liscinsky, Alternative Aviation Fuel Experiment (AAFEX); NASA/TM- 2011- 217059; Hanover, MD, February 2011.

[65] C. H. Huang, R. L. Vander Wal, Effect of soot structure evolution from commercial jet engine burning petroleum based JP-8 and synthetic HRJ and FT Fuels, Energy Fuels 27 (2013) 4946-4958.

[66] R. Q. Casselberry, E. Corporan, M. J. DeWit, Correlation of combustor lean blowout performance to super critical pyrolysis products, Fuel 252 (2019) 504-511.

[67] A. Ergut, Y. A. Levendis, H. Richter, J. B. Howard, J. Carlson, The effect of equivalence ratio on the soot onset chemistry in one-dimensional, atmospheric-pressure, premixed ethylbenzene flames, Combust. Flame 151 (2007) 173-195.

[68] M. V. Heitor, A. L. N. Moreira, Thermocouples and sample probes for combustion studies, Prog. Energy Combust. Sci. 19 (1993) 259-278.

[69] M. S. P. Kahandawala, M. DeWitt, E. Corporan, S. S. Sidhu, Ignition and emission characteristics of surrogate and practical jet fuels, Energy Fuels 22 (2008) 3673-3679.

[70] A. Ergut, S. Granata, J. Jordan, J. Carlson, J. B. Howard, H. Richter, Y. A. Levendis, PAH formation in one-dimensional premixed fuel-rich 
atmospheric pressure ethylbenzene and ethyl alcohol flames, Combust. Flame 144 (2006) 757-772.

[71] H. W. Wong, Z. Yu, M. T. Timko, S. C. Herndon, E. D. L. R. Blanco, R. C. Miake-Lye, R. P. Howard, Design parameters for an aircraft engine exit plane particle sampling system, J. Eng. Gas. Turb. Power. 133 (2010) 021501-1.

[72] J. Mei, M. Wang, X. You, C. K. Law, Quantitative measurement of particle size distributions of carbonaceous nanoparticles during ethylene pyrolysis in a laminar flow reactor, Combust. Flame 200 (2019) 15-22.

[73] C. Gua, H. Lin, J. Camacho, B. Lin, C. Shao, R. Li, H. Gu, B. Guan, Z. Huang, H. Wang, Particle size distribution of nascent soot in lightly and heavily sooting premixed ethylene flames, Combust. Flame 165 (2016) 177-187.

[74] A. D. Abid, J. Camacho, D. A. Sheen, H. Wang, Quantitative measurement of soot particle size distribution in premixed flames-The burnerstabilized stagnation flame approach, Combust. Flame 156 (2009) 1862 1870.

[75] G. R. Salazar-Banda, M. A. Felicetti, J. A. S. Goncalves, J. R. Coury, M. L. Aguiar, Determination of the adhesion force between particles and a flat surface, using the centrifuge technique, Powder. Technol. 173 (2007) 107-117.

[76] H. A. Michelsen, Probing soot formation, chemical and physical evolu- 
tion, and oxidation: A review of in situ diagnostic techniques and needs, Proc. Combust. Inst. 36 (2017) 717-735.

[77] K. A. Anderson, M. J. Szelewski, G. Wilson, B. D. Quimby, P. D. Hoffman, Modified ion source triple quadrupole mass spectrometer gas chromatograph for polycyclic aromatic hydrocarbon analyses, J. Chromatogr. A. 1419 (2015) 89-98.

[78] A. Mueller, N. Ulrich, J. Hollmann, C. E. Z. Sanchez, U. E. RolleKampczyk, M. V. Bergen, Characterization of a multianalyte GCMS/MS procedure for detecting and quantifying polycyclic aromatic hydrocarbons (PAHs) and PAH derivatives from air particulate matter for an improved risk assessment, Environ. Pollut. 255 (2019) 112967.

[79] A. J. Bergmann, G. L. Points, R. P. Scott, G. Wilson, K. A. Anderson, Development of quantitative screen for 1550 chemicals with GC-MS, Anal. Bioanal. Chem. 410 (2018) 3101-3110.

[80] M. Köhler, K. P. Geigle, T. Blacha, P. Gerlinger, W. Meier, Experimental characterization and numerical simulation of a sooting lifted turbulent jet diffusion flame, Combust. Flame 159 (2012) 2620-2635.

[81] J. Du, R.L. Axelbaum, The effect of flame structure on soot particle inception in diffusion flames, Combust. Flame 100 (1995) 367-375.

[82] M. E. Decroix, W. L. Roberts, Transient flow field effects on soot volume fraction in diffusion flames, Combust. Sci. Technol. 160 (2000) 165-189.

[83] Y. Wang, S. H. Chung, Strain rate effect on sooting characteristics in 
laminar counter flow diffusion flames, Combust. Flame 165 (2016) 433444.

[84] M. Frenklach, D. W. Clary, W. C. Gardiner, Jr., S. E. Stein, Detailed kinetic modeling of soot formation in shock-tube pyrolysis of acetylene, Proc. Combust. Inst. 20 (1985) 887-901.

[85] D. Bartos, M. Sirignano, M. J. Dunn, A. D'Anna, A. R. Masri, Soot inception in laminar coflow diffusion flames, Combust. Flame 205 (2019) $180-192$.

[86] M. Frenklach, Reaction mechanism of soot formation in flames, Phys. Chem. Chem. Phys. 4 (11) (2002), pp. 2028-2037.

[87] Y. Minamoto, N. Swaminathan, Scalar gradient behaviour in MILD combustion, Combust. Flame 161 (2014) 1063-1075.

[88] N. Peters, Turbulent combustion, Cambridge University Press, Cambridge, 2000.

[89] A. Bakali, D. Boufflers, C. Betrancourt, P. Desgroux, Experimental and numerical investigation of atmospheric laminar premixed n-butane flames in sooting conditions, Fuel 211 (2018) 548-565.

[90] K. H. Homann, Fullerenes and soot formation-new pathways to large particles in flames, Angew. Chem. Int. Ed. 37 (1998) 2434-2451.

[91] B. Öktem, M. P. Tolocka, B. Zhao, H. Wang, M. V. Johnston, Chemical species associated with the early stage of soot growth in a laminar pre- 
mixed ethylene-oxygen-argon flame, Combust. Flame 142 (2005) 364373.

[92] M. Panariello, B. Apicella, M. Armenante, A. Bruno, A. Ciajolo, N. Spinelli, Analysis of polycyclic aromatic hydrocarbon sequences in a premixed laminar flame by on-line time-of-flight mass spectrometry. Rapid. Commun. Mass. Spectr. 22 (2008) 573-81.

[93] P. Liu, H. Lin, Y. Yang, C. Shao, B. Guan, Z. Huang, Investigating the role of $\mathrm{CH}_{2}$ radicals in the HACA mechanism, J. Phys. Chem. A. 119 (2015) 3261-3268.

[94] K. O. Johansson, J. Y. W. Lai, S. A. Skeen, D. M. Popolan-Vaida, K. R. Wilson, N. Hansen, A. Violi, H. A. Michelsen, Soot precursor formation and limitations of the stabilomer grid, Proc. Combust. Inst. 35 (2015) $1819-1826$.

[95] R. P. Lindstedt, Modeling of the chemical complexities of flames, Proc. Combust. Inst. 27 (1998) 269-285.

[96] L. Wheatley, Y. A. Levendis, P. Vouros, Exploratory study on the combustion and PAH emissions of selected municipal waste plastics, Environ. Sci. Technol. 27 (1993) 2885-2895.

[97] M. Frenklach, Z. Liu, R. I. Singh, G. R. Galimova, V. N. Azyazov, A. M. Mebel, Detailed, sterically-resolved modeling of soot oxidation: Role of $\mathrm{O}$ atoms, interplay with particle nanostructure, and emergence of inner particle burning, Combust. Flame 188 (2018) 284-306. 
${ }_{940}$ [98] M. R. Kholghy, G. A. Kelesidis, S. E. Pratsinis, Reactive polycyclic aromatic hydrocarbon dimerization drives soot nucleation, Phys. Chem.

942 Chem. Phys. 20 (2018) 10926-10938. 